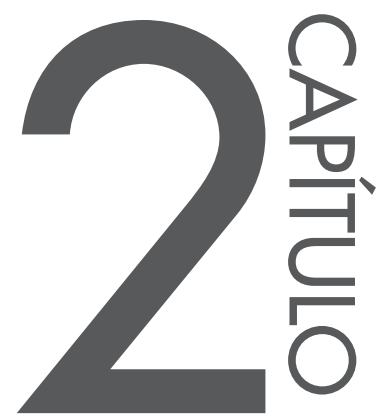

\title{
Módulo ADAMS/View aplicado ao estudo do MHS
}

Este capítulo tem como objetivo iniciar o leitor na utilização do módulo ADAMS/View modelando dois mecanismos clássicos para o estudo do Movimento Harmônico Simples (MHS): o pêndulo físico e o pêndulo simples. Ambos os modelos são criados e a análise dos resultados provenientes das simulações é realizada, utilizando, como aporte, o equacionamento analítico para validação dos mesmos.

Para o pêndulo físico será determinada a força aplicada no vínculo (junta) de rotação. Será realizada uma análise de sensibilidade desta força, alterando-se a massa e velocidade angular do pêndulo. O período de oscilação do sistema também será avaliado em função das variações desses parâmetros.

Já o pêndulo simples será utilizado na determinação numérica da aceleração da gravidade na terra. Equações analíticas validam o modelo virtual.

Os modelos virtuais a serem obtidos ao final deste capítulo estão mostrados a seguir. 

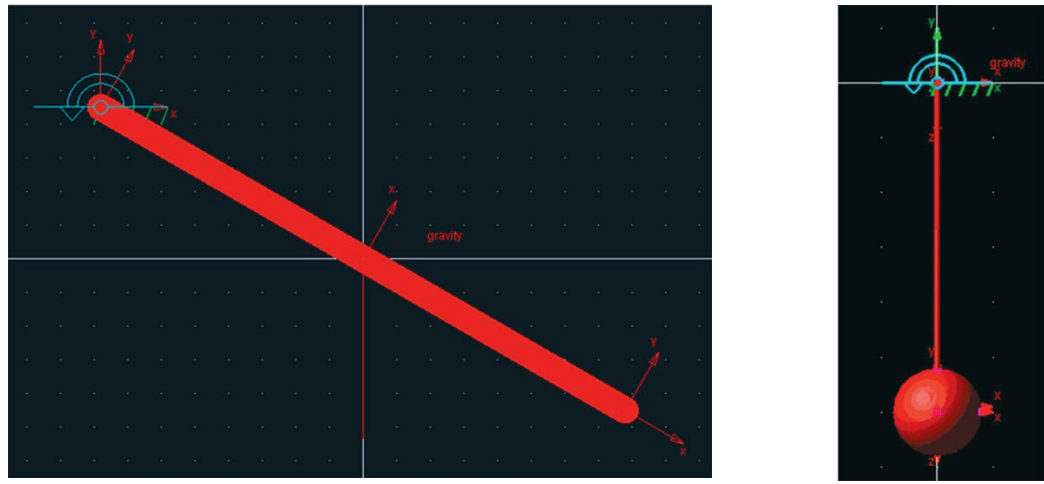

Pêndulo Físico

Pêndulo Simples

\subsection{Desenvolvimento de um modelo virtual de um pêndulo físico}

Este item se dedica à construção e à simulação de um pêndulo físico composto de uma barra homogênea e uniforme de $2,0 \mathrm{~kg}$ e comprimento igual a $450 \mathrm{~mm}$.

A notar: no domínio da Teoria da Elasticidade, diz-se que um corpo é homogêneo quando as propriedades físicas específicas de um elemento infinitesimal deste podem ser extrapoladas para todo o corpo, ou seja, em qualquer ponto desse corpo no espaço as propriedades serão as mesmas.

Diz-se que a mesma é uniforme se não há variação das propriedades geométricas.

A essa barra será imposta uma velocidade angular inicial constante de valor $3 \mathrm{rad} / \mathrm{s}$. A posição inicial do movimento será de $30^{\circ}$ relativamente ao eixo horizontal $x$.

A notar: um pêndulo consiste em um objeto oscilante em torno de um ponto fixo $e$ que tem como principais aplicações estudos da força peso e do movimento oscilatório. Isto lhe garante um caráter de mecanismo de medição ou instrumento. Galileu Galilei, físico, matemático, astrônomo e filósofo italiano foi quem primeiro se dedicou ao estudo da periodicidade do movimento pendular, dando grande contribuição à Mecânica Clássica.

Visto como um objeto oscilante, há duas formas de se tratar um pêndulo: como físico ou simples. O pêndulo físico consiste em um corpo rígido de massa " $m$ ", que oscila em um plano vertical, em torno de um ponto "O" fixo, por onde passa um eixo perpendicular ao plano de oscilação.

Este corpo é sustentado neste ponto, sem atrito e fica a uma distância " $d$ " do seu 
centro de massalcentro de gravidade, conforme mostra a figura a seguir. O pêndulo físico é normalmente aplicado na determinação do valor local da gravidade.

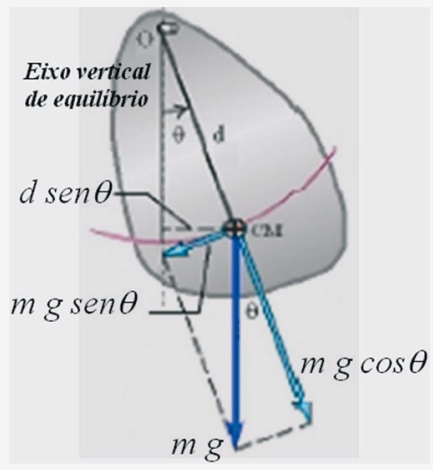

Pêndulo físico.

Fonte: UNIDESC. Disponivel em: <http://www.joinville.udesc.br/portal/professores/vitor Imateriais/Roteiro_7_I.pdf>. Acesso em:22/11/2012

O pêndulo encontra-se em equilíbrio, quando o ponto "O" $\mathrm{O}$ o centro de massa "cm" deste se encontram sobre o mesmo eixo na posição vertical. Quando este é levemente afastado desta posição (pequenas oscilações), ele passa a executar um movimento oscilatório em torno dela, esse movimento é denominado movimento harmônico simples, se não há forças de atrito.

Durante esse movimento, um torque restaurador de valor $\tau=d \times(m g \operatorname{sen} \theta)$ age sobre o pêndulo, no qual $\theta$ é o ângulo entre o eixo vertical de equilíbrio e a reta que posiciona o pêndulo durante seu movimento. O ângulo e o torque restaurador terão sempre sinal contrário, ou seja, se $\theta>0, \tau<0$ e vice-versa, daí a atribuição restaurador. Convenciona-se que valores positivos estão no sentido anti-horário, enquanto valores negativos, no horário.

Com o desenvolvimento deste modelo virtual, deseja-se obter a força aplicada no ponto de apoio no instante $t 0$.

\section{Etapa 1 - Inicializando o ADAMS/View}

- Inicialize o módulo conforme discutido no item 1.3.1 e escolha a opção Create a new model.

- Em seguida, preencha a aba Model name com o nome do modelo virtual, no caso, "pendulo_fisico". Veja este é o nome do modelo virtual.

A Figura 2.1, a seguir, exibe a tela que o usuário irá obter. Ressalta-se que o nome atribuído não deve conter caracteres especiais, como acentos gráficos, símbolos, formas etc. Mantenha a aba Gravity e Units nos valores default, conforme indicado na Figura 2.1. 
$\mathrm{Na}$ aba Start in, especifique o diretório no qual o database será armazenado, quando gravado. No caso, escolheu-se o diretório "Meus documentos" pasta "Minhas Formas".

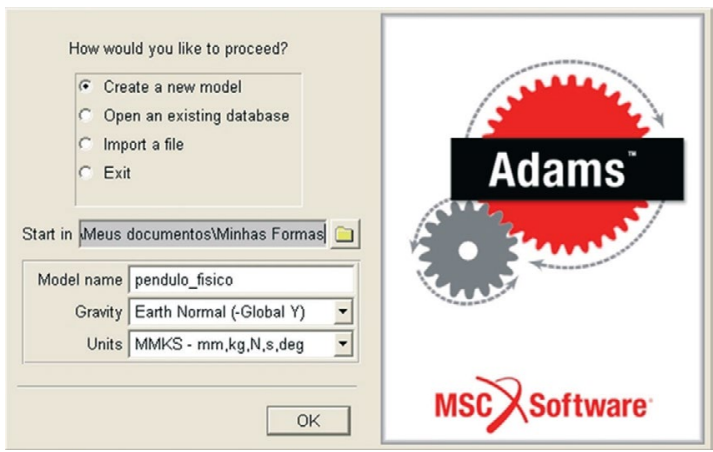

Figura 2.1 - Tela inicial do ADAMS/View.

\section{Etapa 2 - Ajustando a área de trabalho no ADAMS/View}

- Altere o espaçamento do grid para $25 \mathrm{~mm}$. Para tanto, recorra ao menu principal opção Settings $\rightarrow$ Working Grid aba Spacing. A tela auxiliar que aparecerá é a indicada na Figura 2.2.

\begin{tabular}{|c|c|c|c|}
\hline X Worki & ng Grid Sett & ings & $x$ \\
\hline Fv Show & Working Gri & $d$ & 㤟 \\
\hline - Recta & ingular $\subset \mathrm{P}$ & Polar & \\
\hline & $x$ & Y & \\
\hline Size & $(750 \mathrm{~mm})$ & (500 & (mm) \\
\hline Spacing & [25mm] & $(25 n$ & nm) \\
\hline & Color & w & eight \\
\hline Dots & Contrast & 1 & - \\
\hline Axes & Contrast I & 1 & - \\
\hline Lines & Contrast = & 1 & $=$ \\
\hline Triad & Solid & - & \\
\hline Set Loca & tion $=$ & & \\
\hline Set Orie & tation ... $=$ & & \\
\hline OK & Apply & $\mathrm{Ca}$ & ancel \\
\hline
\end{tabular}

Figura 2.2 - Tela para alteração de espaçamento do grid na área de trabalho do ADAMS/View.

Etapa 3 - Construção do corpo rígido - Barra homogênea e uniforme

- Crie uma geometria sólida, no caso um link, conforme tratado no item 1.3.2.1, b.1. 
- $\quad$ Escolha no menu Main Toolbox o ícone referente ao Rigid body: link $\mid \mathbb{Q}$.

- Após seleção da opção, as abas referentes à criação da geometria aparecem nos campos inferiores do menu Main Toolbox, são eles: o comprimento, Length, a largura, Width e a profundidade, Depth, que devem ser preenchidos como ilustrado na Figura 2.3. Cabe ressaltar que para tornar os valores de geometria válidos, o deve-se tornar as abas ativas; isto se faz selecionando cada uma delas com um tick. Tenha atenção às unidades, pois o default da janela é o "cm" e as unidades mostradas estão em “mm”.

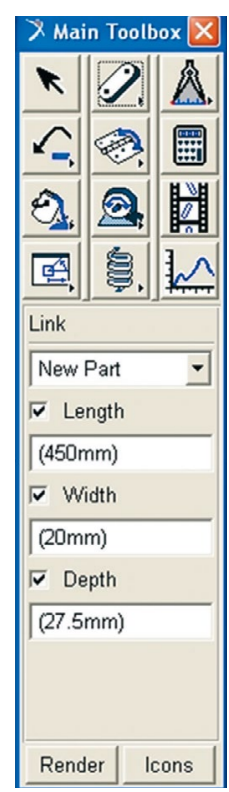

Figura 2.3 - Tela para criação do link que representará a barra homogênea do pêndulo físico.

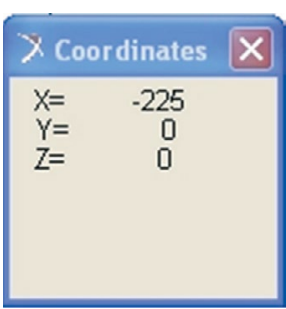

(a)

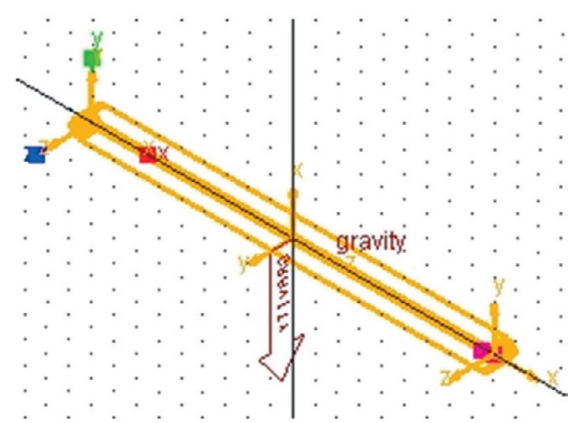

(b)

Figura 2.4 - (a) tela para criação da coordenada inicial do pêndulo físico; (b) link criado na área de trabalho (vista isométrica). 
- Escolha a coordenada inicial do link, segundo as coordenadas (X, Y, Z) iguais a $(-225,0,0)$. Para tanto, posicione o cursor em qualquer ponto da tela e, em seguida, pressione a tecla F4 (Tabela 1.5). Essa operação abrirá uma janela denominada Coordinates, conforme a Figura 2.4a.

- Posicione, então, o cursor na posição desejada. Não clique com o mouse sobre a área de trabalho, pois isto dará início ao comando link. Outra maneira de estabelecer o ponto inicial da geometria é segundo o indicado na Figura 1.28a.

- Em seguida, arraste o cursor para finalização da criação do link até a coordenada $(+225,0,0)$. A Figura $2.4 \mathrm{~b}$ mostra a geometria finalizada em vista isométrica.

- Após a criação do link, Figura 2.4a, selecione-o e pressione o botão direito do mouse sobre ele. A janela que será apresentada é a mostrada na Figura 2.5a. Repare que a seleção se refere à Part:PART_2. Em seguida, como mostrado, selecione a opção Modify.

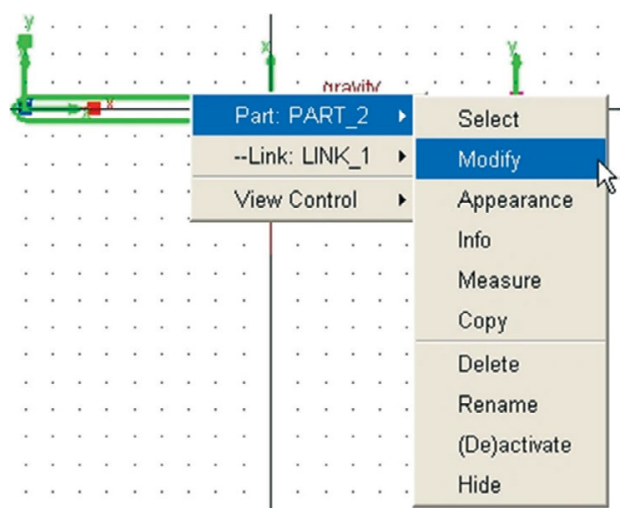

(a)

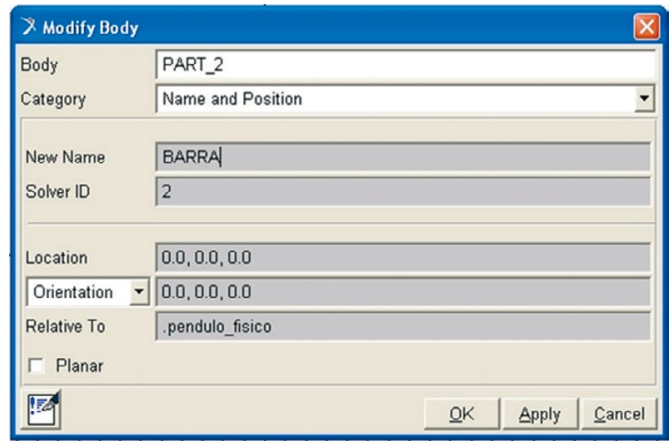

(b)

Figura 2.5 - (a) Tela referente à demanda de modificação de parâmetros do link;

(b) tela referente à opção Modify.

- $\quad \mathrm{Na}$ aba Category, Figura 2.5b, ative a barra de rolagem e escolha a opção Name and Position.

- Na opção Body, Figura 2.5b, aparece o nome PART_2. Vá à aba New Name e digite BARRA, como o novo nome da geometria.

- Em seguida, escolha a opção Apply. Verifique que a aba Body tem seu nome atualizado por BARRA. A tela que concretiza as operações descritas aqui é mostrada na Figura 2.5b.

- Tecle na opção $O k$ para finalizar a operação. 
- Para atribuir a massa de $2 \mathrm{~kg}$ à barra, selecione a geometria, clique com o botão direito do mouse sobre ela e escolha a opção Part: BARRA $\rightarrow$ Modify.

- $\quad \mathrm{Na}$ aba Category escolha a opção Mass Properties e na aba Define Mass By escolha User Input. Repare que para ter acesso a estas opções, deve-se ativar as barras de rolagem ao lado de cada uma das abas. A Figura 2.6 ilustra este passo. Note que a unidade considerada foi o "kg", por isso o valor 2.0.

\section{Etapa 4 - Definindo a posição inicial do pêndulo físico}

- Selecione a geometria sólida.

- No menu Main Toolbox, selecione a opção Position: Reposition Position objects relative to view coordinates ( $x$ to right, $y$ up, $z$ out of the view) ícone 国. Ele se encontra no $1^{\mathrm{o}}$ grupo de ícones, segundo Tabela $1.4,4^{\mathrm{a}}$ linha, $1^{\text {a }}$ coluna.

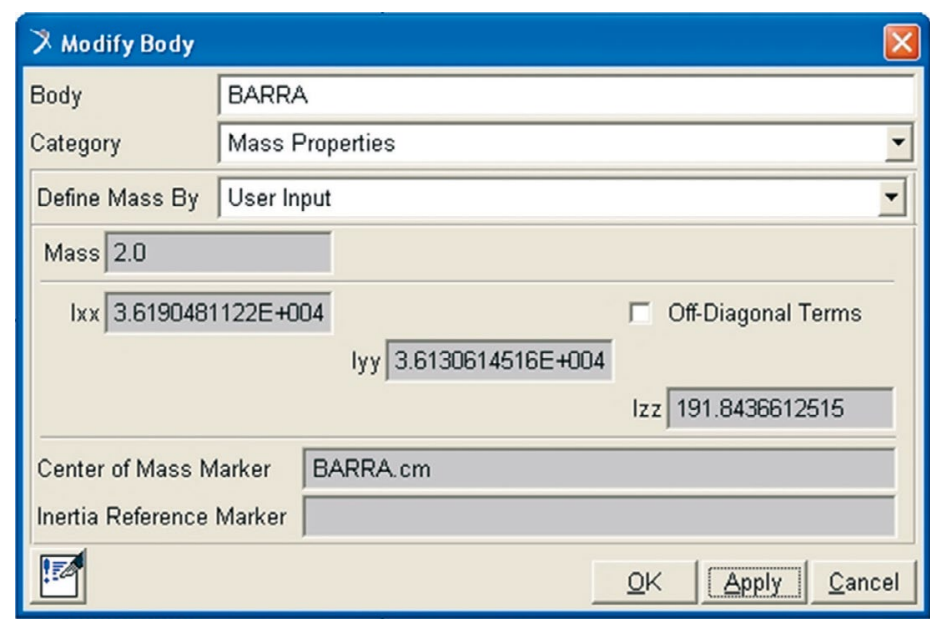

Figura 2.6 - Tela correspondente à atribuição de massa ao modelo virtual.

- Preencha a aba Angle com o valor de $30^{\circ}$.

- Escolha a seta da esquerda no campo Rotate About View Center, no sentido horário. Esta operação fará com que a barra gire segundo o eixo $x$, exatamente como estabelecido em 2.1. As Figuras 2.7a, b ilustram as abas preenchidas e o posicionamento inicial do pêndulo, respectivamente. 


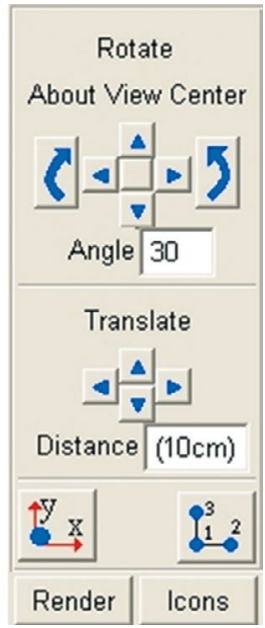

(a)

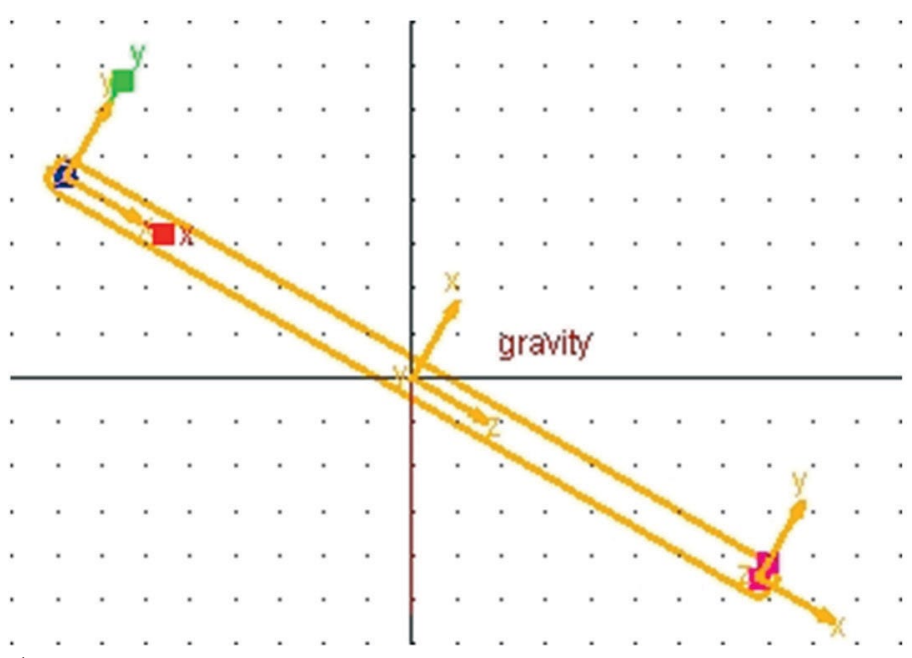

(b)

Figura 2.7 - (a) seleção de valores para posicionamento inicial da barra do pêndulo físico; (b) posição inicial do pêndulo (vista frontal).

\section{Etapa 5 - Estabelecendo restrições ao modelo virtual}

A junta que será colocada no modelo é uma junta idealizada do tipo junta revoluta tratada em 1.3.3.1a.

- Escolha o ícone referente a esta junta no menu Main Toolbox.

- Preencha as abas referentes a esta junta da seguinte maneira: Construction opção 1 Location e, em seguida, na aba logo abaixo, Normal to Grid, Figura 2.8a. Neste caso, ao fornecer a posição de inserção, o ADAMS/View automaticamente selecionará as partes necessárias para inserção da restrição, no caso o link e o ground part.

- Posicione o mouse sobre a extremidade superior da barra e, com o botão esquerdo do mouse sobre a geometria, selecione o marker correspondente a essa extremidade, no presente modelo BARRA: MARKER_1, Figura 2.8b. A Figura $2.8 \mathrm{c}$ mostra o resultado final. 


\begin{tabular}{|l|}
\hline Revolute Joint \\
\hline Construction: \\
\hline 1 Location \\
\hline Normal To Grid - \\
\hline
\end{tabular}

(a)

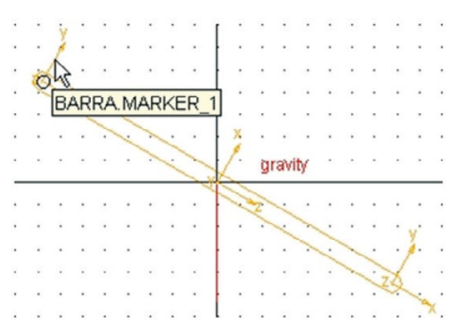

(b)

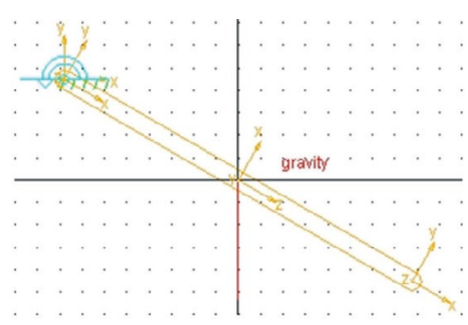

(c)

Figura 2.8 - (a) preenchimento das abas para inserção de uma junta revoluta;

(b) seleção do marker para inserção da junta;

(c) resultado final após inserção da junta.

\section{Etapa 6 - Definição do movimento inicial do modelo}

A velocidade angular inicial de $\omega=3 \mathrm{rad} / \mathrm{s}$ será atribuída ao modelo a partir da escolha de um marker que se encontra no ground part. O usuário pode verificar a posição desse marker clicando com o botão direito do mouse sobre o centro da junta revoluta inserida. Ao clicar, aparecerão duas informações: Part: BARRA e Part: ground.

A primeira parte traz um link e dois markers e a segunda, um marker e uma junta (joint). O usuário perceberá que para inserir o movimento inicial deverá escolher o Marker: MARKER_4 pertencente ao Part: ground. Assim,

- Selecione o modelo com o mouse.

- Pressione o botão direito do mouse sobre o mesmo e escolha Part: BAR$R A \rightarrow$ Modify.

- $\quad \mathrm{Na}$ aba Category, ative a barra de rolagem e escolha Velocity Initial Conditions. Será possível perceber que a janela se divide em duas áreas: Translational velocity along e Angular velocity about. Vá para a área Angular velocity about.

- Selecione a opção Marker.

- Uma caixa de texto aparece. Clique com o botão direito do mouse sobre ela. Na janela auxiliar, escolha a opção Marker. Expanda esta aba e vá à opção Guesses. Expanda esta opção e escolha ".pendulo_fisico. ground:MARKER_4".

- $\quad$ Entre as opções de eixo mostradas, escolha a opção $Z$ axis. Preencha a caixa de texto lateral de fundo cinza com o valor de $3.0 \mathrm{r}$. Não coloque unidades e perceba a letra " $r$ " ao final.

- Clique em Apply, neste momento o valor será alterado, e, em seguida, Ok. A Figura 2.9 ilustra esta Etapa. 


\section{Etapa 7 - Verificação do modelo}

Esta Etapa se destina à análise do modelo antes que ele seja submetido à simulação. Para tanto,

- Clique no ícone i. com o botão direito do mouse. Este ícone se situa no canto inferior direito da tela do ADAMS/View.

- Escolha a opção $\checkmark$. Ela verifica o modelo, fornece o número de partes e informa o número de graus de liberdade.

- Feche a tela correspondente, se a mensagem ao final for Model verified successfully.

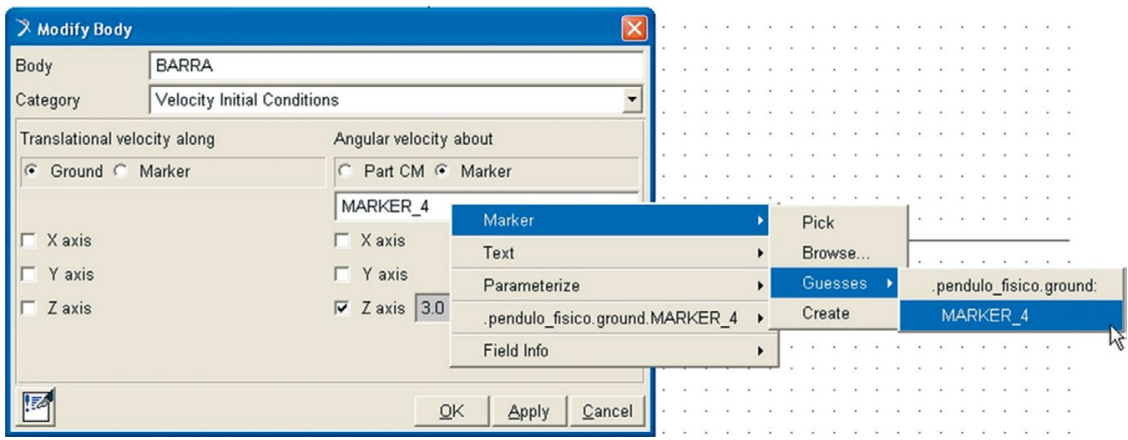

Figura 2.9 - Tela ilustrativa da Etapa 6.

\section{Etapa 8 - Simulação do modelo}

- Clique no centro da junta revoluta e acione o botão direito do mouse.

- Selecione a opção Joint:Joint_1 e escolha a opção Measure.

- Vá à aba Characteristic, acione a barra de rolagem e escolha a opção Force.

- $\quad \mathrm{Na}$ aba Component, selecione mag.

- Mantenha as demais abas preenchidas com os valores default. A Figura 2.10a exibe como deve ser preenchida a tela.

- Clique em Apply e, nesse momento, uma tela indicativa da medida (Measure) inserida irá aparecer, conforme a Figura 2.10b. Não feche a tela, pois será nela que aparecerão os resultados requeridos sobre o pêndulo.

- Para finalizar, Clique em Cancel. Se clicar em $O k$, uma nova tela idêntica à anterior (Figura 2.10b) irá aparecer. 


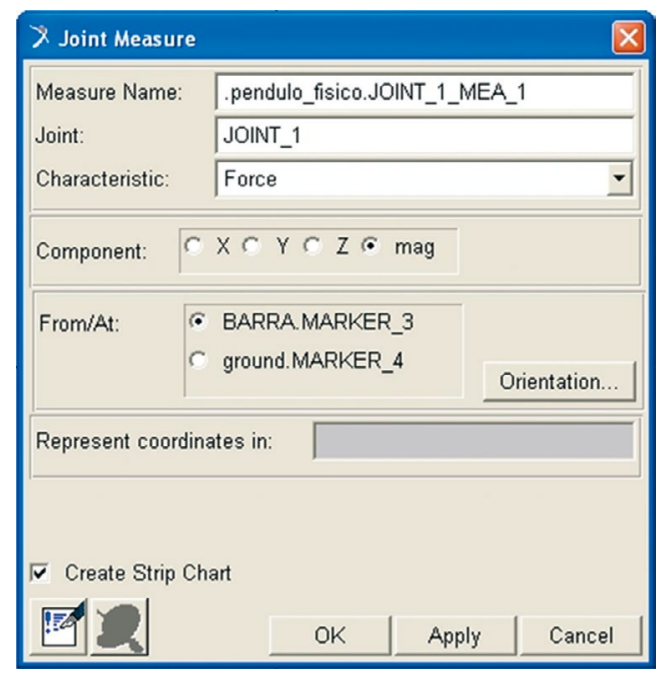

(a)

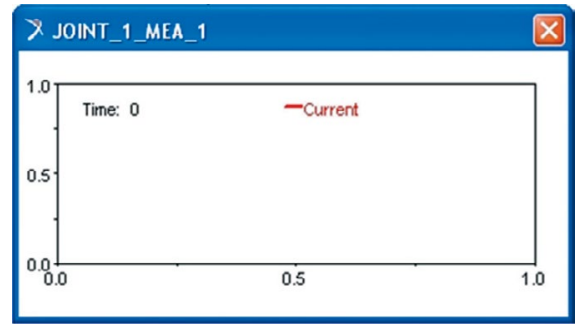

(b)

Figura 2.10 - (a) preenchimento correspondente ao início da simulação;

(b) tela resultante da operação efetuada.

- Em seguida, vá ao menu principal Main Toolbox e selecione o ícone 娄, tratado no item 1.3.4, com um simples clique sobre ele.

- Preencha as abas que aparecem na parte inferior do menu Main Toolbox, conforme mostrado na Figura 2.11a. Em seguida, clique no botão Play - . A tela JOINT_1_MEA_1 será preenchida conforme a Figura 2.11b. 


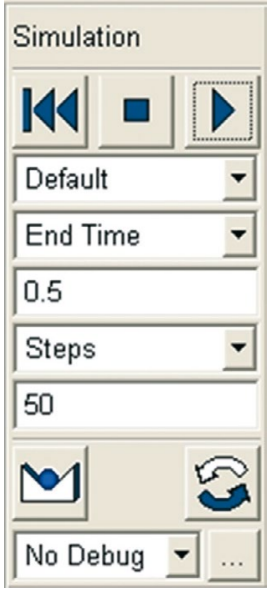

(a)

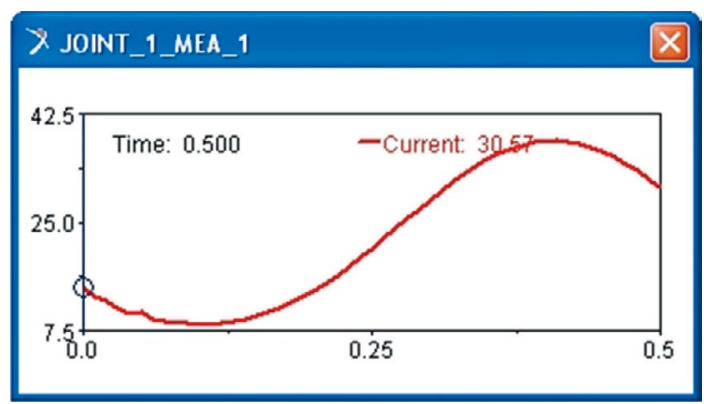

(b)

Figura 2.11 - (a) Preenchimento das abas referentes à simulação;

(b) gráfico gerado após simulação

Etapa 9 - Determinação da força sobre o ponto de inserção da junta

Para a realização desta Etapa, será necessário recorrer ao ADAMS/ PostProcessor, tratado no item 1.4.

- Clique com o botão direito do mouse em qualquer ponto da área do gráfico JOINT_1_MEA_1.

- Aparecerá então a opção Plot:scht1.

- Expanda e selecione a opção Transfer to full plot. Neste momento você irá migrar para o módulo ADAMS/PostProcessor.

- No menu principal deste módulo, selecione a opção Plot Tracking repre-

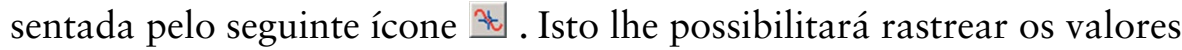
de Força $x$ Tempo ao longo da curva.

Verifica-se que o pêndulo está submetido a uma força máxima de $38,12 \mathrm{~N}$ aos 0,41 s e a uma força mínima de $8,54 \mathrm{~N}$ a $0,1 \mathrm{~s}$. No ponto em que $x$ é igual a zero, o valor da força é de $14,54 \mathrm{~N}$. A pequena instabilidade no início da curva se deve à entrada em movimento do mecanismo. A Figura 2.12 mostra a aparência dessa janela.

- Pressione a tecla F8 para retornar ao módulo ADAMS/View.

\section{Etapa 10 - Salvando o modelo virtual}

Após finalizar a simulação, o usuário deve salvar seu trabalho procedendo da seguinte maneira:

- Vá ao menu principal do módulo e selecione a opção File. 
- Clique sobre ela e a faça expandir.

- Escolha a opção Save Database as...

- Clique sobre ela e uma tela irá se abrir, conforme a Figura 2.13.

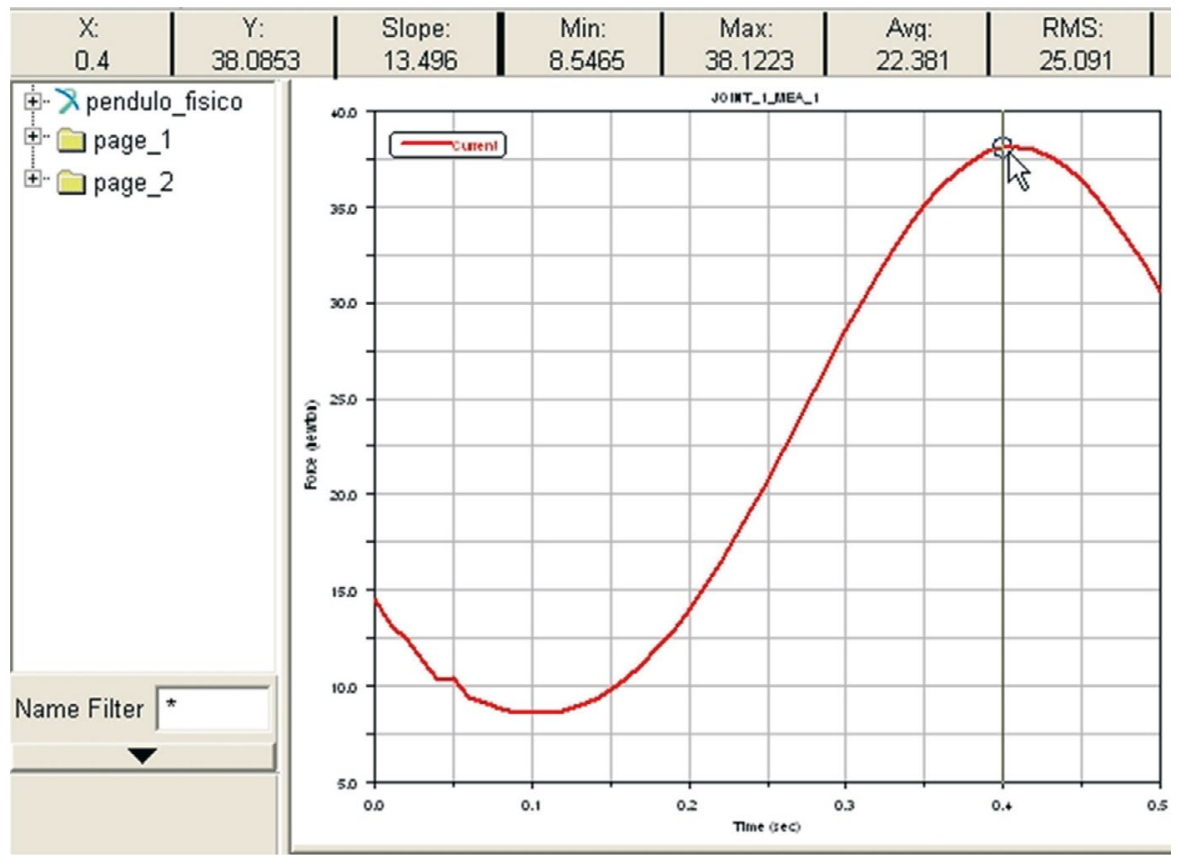

Figura 2.12 - Variação da força no vínculo ao longo de um período de oscilação de $0,5 \mathrm{~s}$.

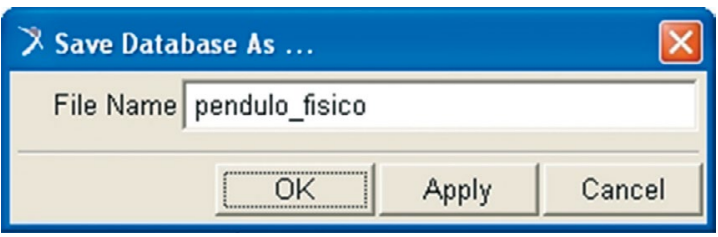

Figura 2.13 - Tela para gravação do modelo virtual.

- $\quad$ Clique na opção $O k$.

Cabe ressaltar que o nome do arquivo aparece automaticamente e é igual ao nome do modelo com extensão *. *bin. O local onde ele será armazenado foi definido no início da seção na aba Start in, sendo esta preenchida por *.*/Meus documentos/Minhas Formas. 


\section{Etapa 11 - Comparação entre os valores de força encontrados pelo} ADAMS/View e analiticamente

A notar: A resolução analítica do problema do pêndulo físico remete ao seguinte equacionamento do problema.

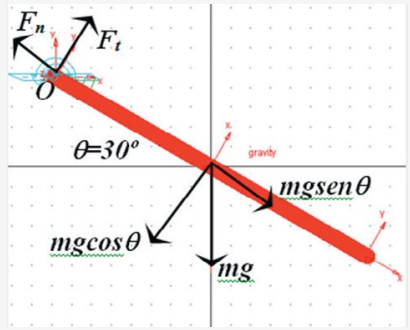

Considere a figura acima representativa do pêndulo físico em que no ponto " $\mathrm{O}$ " agem as forças Ft e Fn, que são, respectivamente, forças tangencial e normal ao polo O. A força peso age no centro de massalcentro de gravidade da barra homogênea e uniforme e se decompõe segundo as componentes mostradas: mgcos $\theta$ no sentido tangencial e mgsen $\theta$ no sentido normal.

O somatório do momento em torno do polo "O" é igual a:

$$
\sum M^{0}=I_{0} \alpha(1)
$$

onde IO é o momento de inércia da barra em torno de " $\mathrm{O}$ ” $e$ a a aceleração tangencial. A única força capaz de gerar momento em torno desse ponto é a componente do peso $m g \cos \theta$ que multiplicado pelo braço de alavanca " $d$ ", distância ao longo da barra entre o ponto de aplicação da força até " $\mathrm{O}$ ”, fornece:

$$
m g \cos \theta d=I_{0} \alpha \quad(2)
$$

Sabendo que o momento de inércia de uma barra em seu centro de massa é: $I_{C M}=\frac{m L^{2}}{12}$ , onde " $m$ " é a massa da barra e "L" seu comprimento total. Como se precisa do momento de inércia no ponto "O”, aplicando o Teorema dos Eixos Paralelos tem-se: $I_{0}=\frac{m L^{2}}{3}$ s2; $d=0,225 \mathrm{~m} e=30^{\circ}$, obtém-se a igual a 28,32 rad/ $\mathrm{s} 2$.

O equilíbrio das forças nas direções tangencial e normal geram:

$$
\begin{gathered}
\sum F_{t}=m d \alpha \\
m g \cos \theta-A_{t}=m d \alpha \\
e \\
\sum F_{n}=m d w^{2} \\
A_{n}-m g \operatorname{sen} \theta=m d w^{2}
\end{gathered}
$$

De a igual a 28,32 rad/s2 e w=3,0rad/s, tiram-se de (3) e (4) os valores de At e An, respectivamente, sendo estes iguais a 4,247N e 13,86N. A resultante de F é calculada usando o Teorema de Pitágoras, levando ao valor de 14,5N. 
O valor discriminado no quadro acima é aproximadamente o mesmo determinado pela simulação do pêndulo no ponto $\mathrm{x}=0$, ou seja, $14,54 \mathrm{~N}$.

\subsubsection{Estudo de sensibilidade do modelo virtual}

Neste tópico será avaliada a sensibilidade do modelo virtual criado a partir da realização do seguinte experimento:

- Dobre a massa da barra, que passará de 2,0 kg para 4,0 kg e velocidade angular inicial de $3 \mathrm{rad} / \mathrm{s}$.

- Mantenha a massa da barra em 2,0 kg e multiplique por um fator de escala 2,0 o valor da velocidade angular inicial, ou seja, a mesma passará de $3,0 \mathrm{rad} / \mathrm{s}$ para $6,0 \mathrm{rad} / \mathrm{s}$.

\subsubsection{Alterando o valor da massa do pêndulo físico}

Os resultados destas duas operações serão comparados em seguida. Comece alterando a massa da barra.

- Modifique a massa da barra clicando com o botão direito do mouse sobre a barra.

- Selecione PART:BARRA e clique em Modify. Será aberta a tela auxiliar correspondente a essa opção, Figura 2.6. Coloque a aba Category em Mass Properties e a aba Define Mass By em User Input.

- $\quad \mathrm{Na}$ aba Mass digite o valor 4.0.

- Repita a Etapa 8.

- $\quad$ Como na Figura 2.10a, crie um novo nome para a aba Measure Name. Sugestão: JOINT_1_MEA_m4kg.

- Selecione o ícone 娄, no menu Main Toolbox e proceda como indicado na Etapa 8. Na Figura 2.11a escolha 1.0 para a aba End time.

- Prossiga repetindo o estabelecido na Etapa 9. 


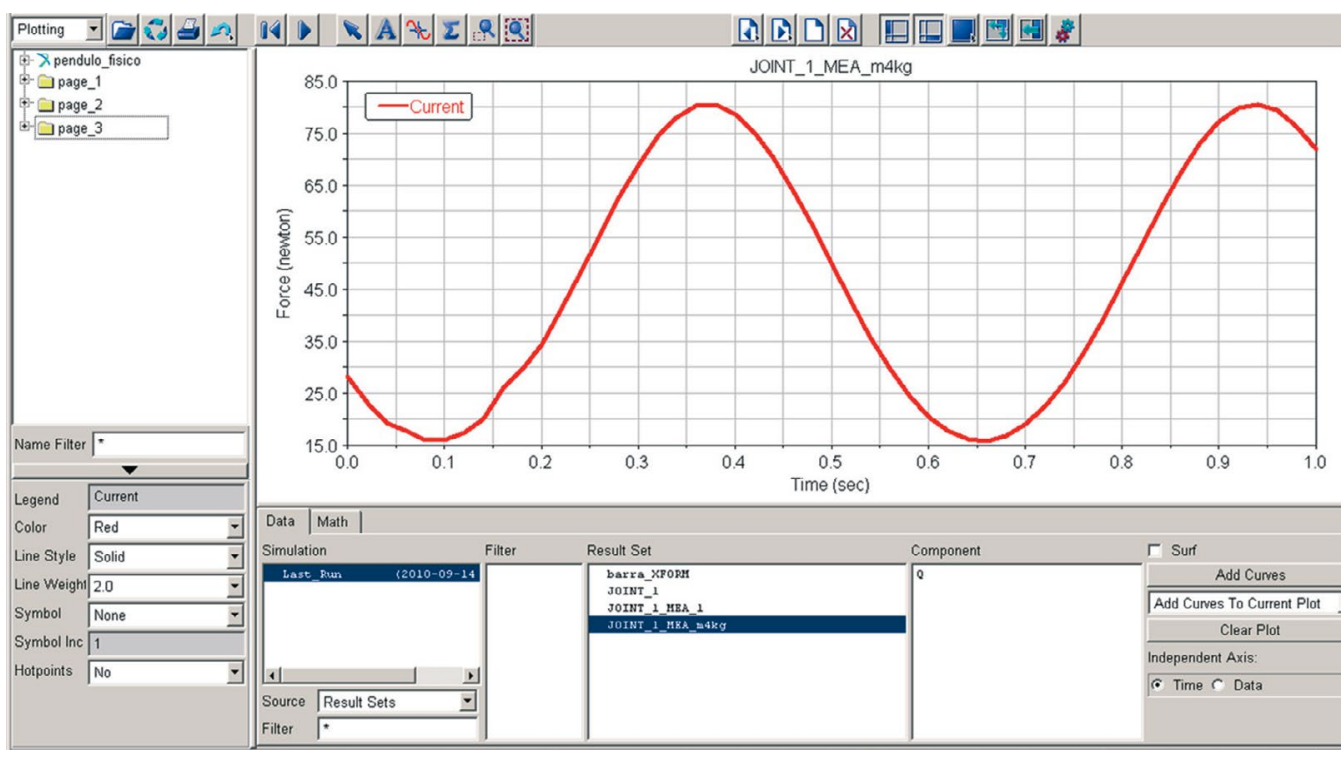

Figura 2.14 - Variação da força no vínculo ao longo de um período de oscilação de $1,0 \mathrm{~s}$ considerando a massa da barra igual a $4,0 \mathrm{~kg}$.

Note que à esquerda da tela foi criada uma pasta de nome page_3 que contém os dados desta simulação.

- Pressione F8, retornando ao ambiente do ADAMS/View e refaça o dito acima com a massa da barra sendo igual a $2 \mathrm{~kg}$. Esta operação deve ser repetida para que se amplie o período de oscilação, que antes, para essa mesma massa, era de 0,5 s. Ao estabelecer o nome da nova simulação sugere-se que a aba Measure Name seja preenchida com JOINT_1_ $M E A \_\mathrm{m} 2 \mathrm{~kg}$.

Para comparar os resultados obtidos, variando a massa da barra, exiba as duas curvas no mesmo gráfico. Para tanto, no ambiente ADAMS/PostProcessor:

- Selecione a curva da primeira simulação, ou seja, a curva contendo os resultados da barra de massa igual a $4 \mathrm{~kg}$, a qual está armazenada na page_3. Ela deve ficar iluminada.

- $\quad \mathrm{Na}$ caixa de diálogo Source $\rightarrow$ Result Sets, localizada no canto inferior esquerdo da tela do ADAMS/PostProcessor, selecione a outra curva de interesse, neste caso a JOINT_1_MEA_m2kg, Figura 2.15.

- Na caixa de diálogo Component, parte inferior da tela do ADAMS/ PostProcessor, selecione a variável de interesse, neste caso a variável $\mathrm{Q}$ (Força). Clique em Add Curves, aba no canto inferior direito da tela do ADAMS/PostProcessor, Figura 2.15. 
Verifique que o valor da nova força para $\mathrm{m}=4 \mathrm{~kg}$, no ponto $\mathrm{x}=0$ é de 28,17 $\mathrm{N}$, praticamente o dobro da força anteriormente encontrada para o mesmo ponto.

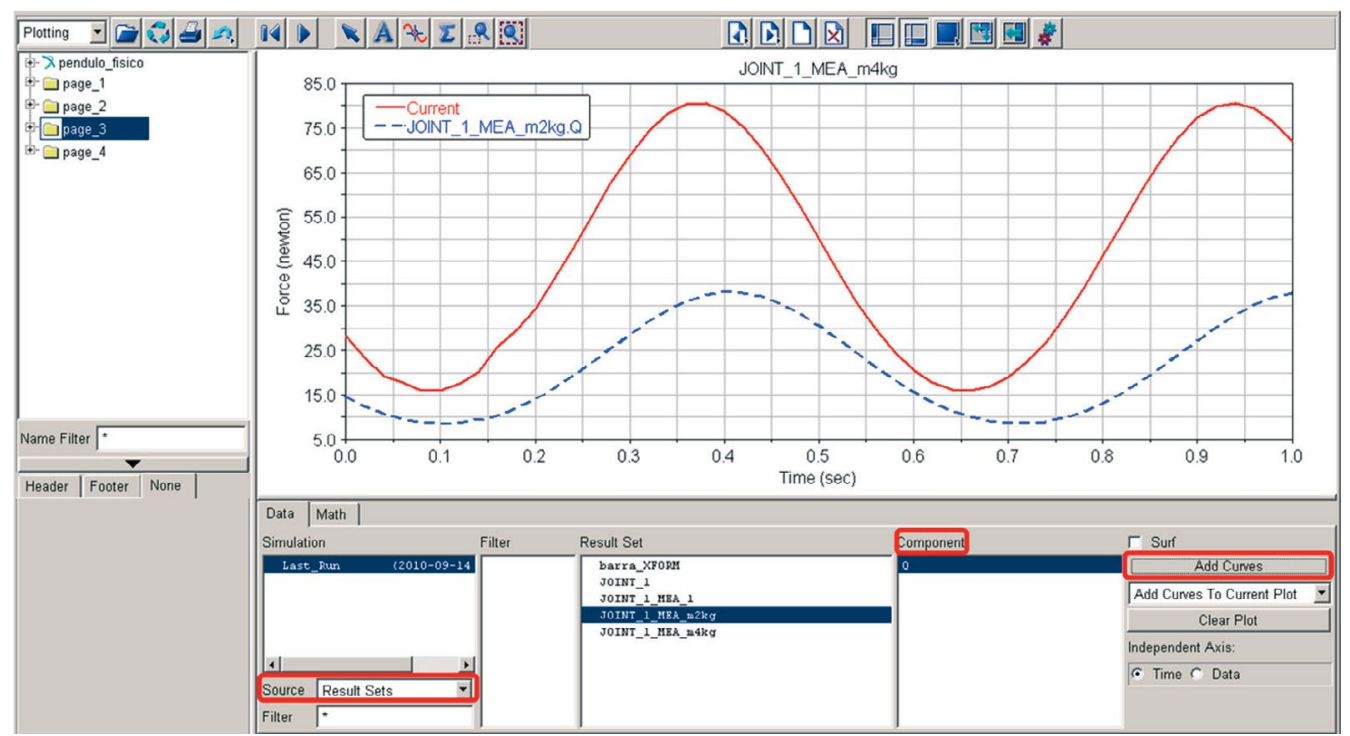

Figura 2.15 - Variação da força no vínculo ao longo de um período de oscilação de 1,0 s considerando as massas das barras iguais a 2,0 e 4,0 kg.

\subsubsection{Alterando o valor da velocidade angular inicial}

Em seguida, será guardado o mesmo valor de massa da barra $\mathrm{m}=2 \mathrm{~kg}$ e a velocidade angular inicial será dobrada, ou seja, passará a $6 \mathrm{rad} / \mathrm{s}$. Para tanto:

- Clique com o botão direito do mouse sobre a barra do pêndulo, selecione PART: BARRA e clique em Modify. Será aberta uma tela semelhante a Figura 2.6.

- $\quad \mathrm{Na}$ aba Category, selecione a opção Velocity Initial Conditions ativando a barra de rolagem.

- Substitua o valor presente na caixa de texto de fundo cinza, ao lado do $Z$ axis, por $6.0 \mathrm{r}$.

- Clique em Apply. Observe que ao fazê-lo o valor em frente à opção muda para 343.7746770795. Em seguida, clique em Ok.

- Selecione novamente a barra e clique com o botão direito do mouse sobre ela, selecione, em seguida, PART: BARRA e escolha a opção Modify.

- $\quad \mathrm{Na}$ aba Category, selecione a opção Mass Properties. 
- $\quad \mathrm{Na}$ aba Define Mass By, escolha User Input como opção, por meio da barra de rolagem.

- Na opção Mass, escreva 2.0. Clique em Apply, em seguida Ok.

- Repita a Etapa 8. Sugere-se que a aba Measure Name tenha seu nome trocado para JOINT_1_MEA_w6rads.

- Selecione o ícone 娄, no menu Main Toolbox e proceda como indicado na Etapa 8. Na Figura 2.11a, escolha 1.0 para a aba End time.

- Prossiga repetindo o estabelecido na Etapa 9.

- Selecione novamente a barra e refaça colocando a velocidade angular inicial igual a $3.0 \mathrm{rad} / \mathrm{s}$, mantendo a mesma massa.

- $\quad$ Repita a Etapa 8. Sugere-se que a aba Measure Name tenha seu nome trocado para JOINT_1_MEA_w3rads.

- Selecione o ícone 圈, no menu Main Toolbox e proceda como indicado na Etapa 8. Na Figura 2.11a escolha 1.0 para a aba End time.

- Prossiga repetindo o estabelecido na Etapa 9.

- Selecione a curva da primeira simulação, ou seja, a curva contendo os resultados da barra de velocidade angular inicial igual a $6 \mathrm{rad} / \mathrm{s}$, a qual está armazenada na page_4. Ela deve ficar iluminada.

- Na caixa de diálogo Source $\rightarrow$ Result Sets, localizada no canto inferior esquerdo da tela do ADAMS/PostProcessor, selecione a outra curva de interesse, neste caso, a JOINT_1_MEA_w3rads, Figura 2.16.

- Na caixa de diálogo Component, parte inferior da tela do ADAMS/ PostProcessor, selecione a variável de interesse, neste caso, a variável Q (Força).

- Clique em Add Curves, aba no canto inferior direito da tela do ADAMS/ PostProcessor, Figura 2.16.

A curva em traço cheio, mostrada na Figura 2.16, se refere à velocidade angular inicial de $\omega=3,0 \mathrm{rad} / \mathrm{s}$, enquanto a outra se refere à velocidade de $\omega=6,0$ $\mathrm{rad} / \mathrm{s}$. Repare que há uma defasagem entre as curvas. 


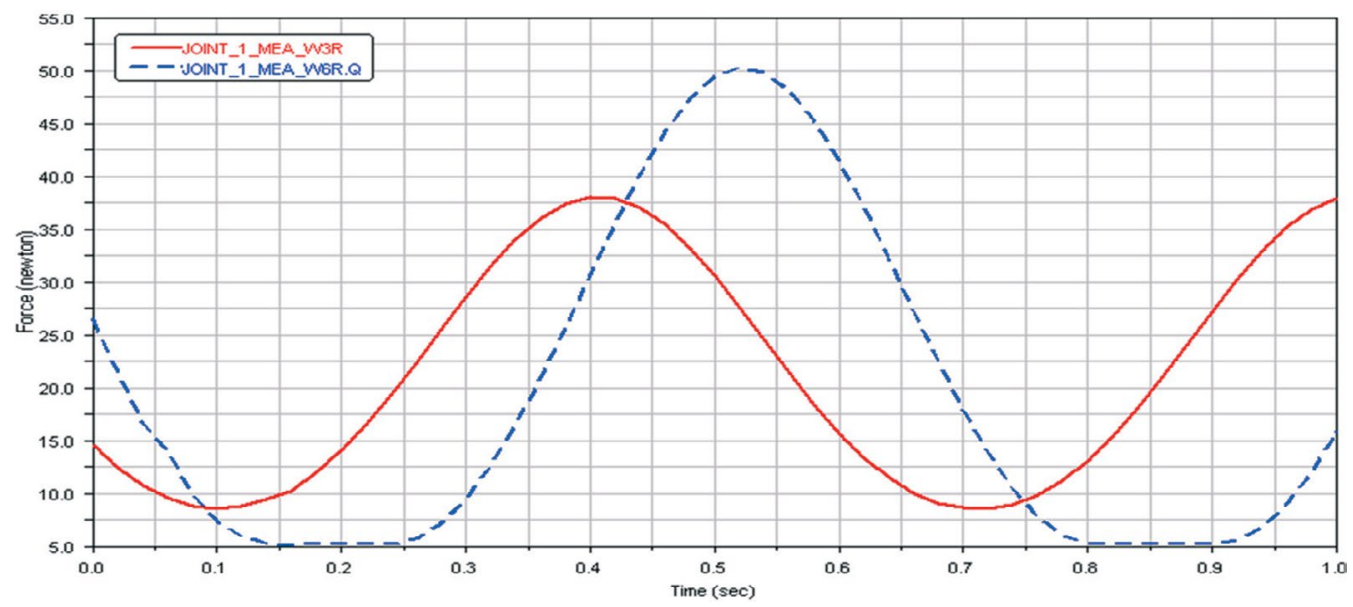

Figura 2.16 - Variação da força no vínculo ao longo de um período de oscilação de 1,0 s considerando as velocidades angulares iniciais da barra iguais a 3 e $6 \mathrm{rad} / \mathrm{s}$.

\subsubsection{Avaliação dos resultados obtidos}

Como na situação mostrada no item 2.1.1.1, o valor da força exercida no ponto de apoio do pêndulo físico no caso do item 2.1.1.2, é praticamente o dobro.

A frequência angular e o período de oscilação do pêndulo físico são dados, respectivamente, por:

$$
f=\sqrt{\frac{m g d}{I_{0}}}
$$

2.1

onde os valores das variáveis das equações já foram previamente definidos em 2.1 - Etapa 11.

Avaliando as duas situações apresentadas em 2.1.1.1 e 2.1.1.2 relativas à frequência angular e ao período de oscilação do pêndulo, tem-se o mostrado na Tabela 2.1. 
Tabela 2.1 - Valores de período e de frequência do pêndulo físico sob diferentes situações

\begin{tabular}{|c|c|c|c|c|c|}
\hline \multicolumn{2}{|c|}{$\begin{array}{c}\text { Caso } 1 \text { - Valor de } \mathrm{m}=2 \mathbf{k g} \\
\text { e } \omega=3,0 \mathrm{rad} / \mathrm{s} \\
\text { (caso referência) }\end{array}$} & \multicolumn{2}{|c|}{$\begin{array}{c}\text { Caso } 2 \text { - Valor de m }=4 \mathrm{~kg} \\
\text { e } \omega=3,0 \mathrm{rad} / \mathrm{s}\end{array}$} & \multicolumn{2}{|c|}{$\begin{array}{c}\text { Caso } 3 \text { - Valor de } \mathrm{m}=2 \mathrm{~kg} \\
\text { e } \omega=6,0 \mathrm{rad} / \mathrm{s}\end{array}$} \\
\hline$f$ & $T$ & $f$ & $T$ & $f$ & $T$ \\
\hline $5,72 \mathrm{~Hz}$ & $1,10 \mathrm{~s}$ & $5,72 \mathrm{~Hz}$ & $1,10 \mathrm{~s}$ & $5,72 \mathrm{~Hz}$ & $1,10 \mathrm{~s}$ \\
\hline
\end{tabular}

A partir dos casos 1, 2 e 3, comprova-se que, como esperado, as frequências e os períodos de oscilação do pêndulo físico são iguais em todos os casos.

Isto porque as grandezas dependem, exclusivamente, do comprimento do pêndulo $(L)$ ou da distância de seu centro de massa ao polo "O" $(d=L / 2)$, que é mantido constante nos três casos. Observa-se que o efeito do fator multiplicativo da massa se anula no quociente da Equação 2.1 e é independe da velocidade angular inicial.

Contudo, percebe-se uma diferença de amplitude entre as curvas (valores máximos e mínimos) com respeito aos valores da força. A Tabela 2.2 traz um comparativo entre esses valores em intervalos de tempo comum.

Tabela 2.2 - Comparação entre as forças em intervalos de tempo comum no pêndulo físico

$$
\begin{array}{ccc}
\text { Caso } 1 \text { - Valor de } \mathrm{m}=2 \mathrm{~kg} & \text { Caso } 2-\text { Valor de } \mathrm{m}=4 \mathrm{~kg} & \text { Caso } 3-\text { Valor de } \mathrm{m}=2 \mathrm{~kg} \\
\text { e } \omega=3,0 \mathrm{rad} / \mathrm{s} & \text { e } \omega=3,0 \mathrm{rad} / \mathrm{s} & e \omega=6,0 \mathrm{rad} / \mathrm{s}
\end{array}
$$

(caso referência)

\begin{tabular}{c|c|c|c} 
Tempo (s) & Força (N) & Força (N) & Força (N) \\
\hline 0,0 & 14,54 & 28,17 & 26,38 \\
\hline 0,12 & 8,77 & 17,51 & 5,85 \\
\hline 0,40 & 38,16 & 78,76 & 31,13 \\
\hline 0,70 & 8,56 & 19,13 & 17,41 \\
\hline 0,88 & 24,46 & 73,32 & 5,11 \\
\hline
\end{tabular}

Da Figura 2.15 e Tabela 2.2 percebe-se que no caso 2 as forças resultantes ao longo da trajetória no ponto "O" (apoio) são sempre superiores que as obtidas no caso 1 . Contudo, em alguns pontos, a razão entre elas varia. Por exemplo, em $x=0$ este fator é de aproximadamente 2,0 , mas em $x=0,88$ s essa razão passa a ser 3,0. Isto se deve a diferenças no valor das forças componentes normal e 
tangencial provocado pela diferença de massa, em um dado ponto num determinado tempo.

Da Figura 2.16 e Tabela 2, verifica-se que a aceleração tangencial permanece a mesma entre os casos 1 e 3, havendo diferença apenas na componente normal, em razão do valor da velocidade angular inicial que varia.

A defasagem entre as curvas de força com respeito aos casos em que $\omega=3,0$ $\mathrm{rad} / \mathrm{s}$ e $6,0 \mathrm{rad} / \mathrm{s}$ se explica pela defasagem observada nas curvas de deslocamento ao longo do eixo $y$. Isto porque a diferença entre as velocidades angulares iniciais garante que um dos pêndulos esteja sempre à frente do outro por ter uma velocidade maior.

A Figura 2.17 esclarece o dito acima em que a curva de traço contínuo se refere à situação de deslocamento para $\omega=3,0 \mathrm{rad} / \mathrm{s}$ e a tracejada para $\omega=6,0 \mathrm{rad} / \mathrm{s}$.

Para obter esse gráfico, recorre-se ao ADAMS/PostProcessor seguindo a sequência de ações semelhante àquela de 2.1.1.2, diferenciando-se apenas nos aspectos mostrados a seguir, além de nomes distintos para os Measures. Para tanto,

- Para definir os pontos de medida, não mais escolha Joint: JOINT_1, mas sim a BARRA e no caso, PART: BARRA. Clique com o botão direito do mouse sobre ela para definir o tipo de medida por meio da opção Measure.

- Na tela Part Measure, no campo Characteristic selecione ativando a barra de rolagem CM position. No campo Component, selecione $Y$.

Para a plotagem dos resultados proceda como especificado em 2.1.1.2. Para tanto, atenção aos seguintes pontos:

- Selecione a curva da primeira simulação, ou seja, a curva contendo os resultados do pêndulo com velocidade angular inicial igual a $6 \mathrm{rad} / \mathrm{s}$. Ela deve ficar iluminada.

- Na caixa de diálogo Source, localizada no canto inferior esquerdo da tela do ADAMS/PostProcessor, escolha a opção Measures ativando a barra de rolagem.

- Selecione a outra curva de interesse, tendo atenção ao nome atribuído ao conjunto de valores.

- Clique em Add Curves, aba no canto inferior direito da tela do ADAMS/ PostProcessor. 


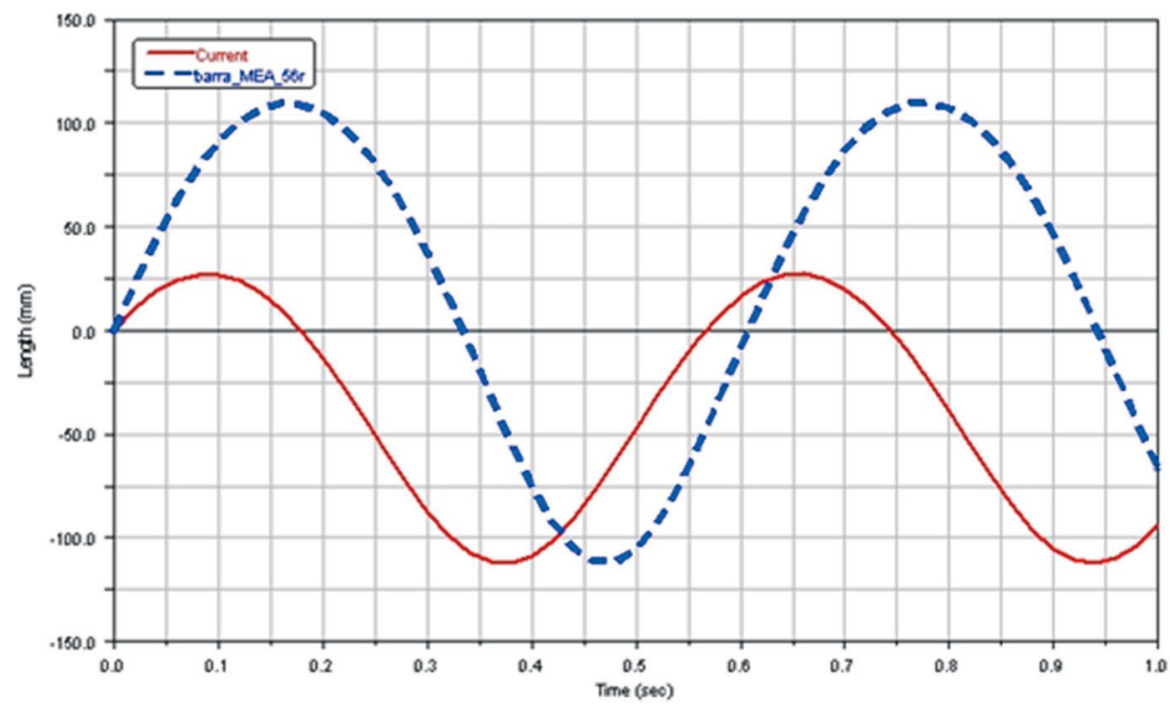

Figura 2.17 - Variação do deslocamento no período de oscilação de 1,0 s considerando as velocidades angulares iniciais da barra iguais a 3 e $6 \mathrm{rad} / \mathrm{s}$.

\subsection{Desenvolvimento de um modelo virtual de um pêndulo simples}

A notar: define-se o pêndulo simples como um corpo formado por uma partícula suspensa por um fio inextensivel de massa desprezivel. Quando afastado de sua posição de equilíbrio e solto, esse pêndulo oscilará em um plano vertical, em torno de um eixo perpendicular ao plano de movimento.

A oscilação se deve à ação da gravidade e o movimento é periódico possibilitando o cálculo da frequência e do período de oscilação.

A figura ao lado mostra um pêndulo simples de comprimento L e massa da partícula igual a m. Perceba que comparativamente ao pêndulo físico, o pêndulo simples tem seu centro de massa/centro de gravidade situado na extremidade do fio e, não mais no ponto $L / 2=d$, conforme visto anteriormente.

O pêndulo simples é visto como uma massa oscilante pontual. Sendo assim não será mais necessário o cálculo de um momento de inércia polar. 


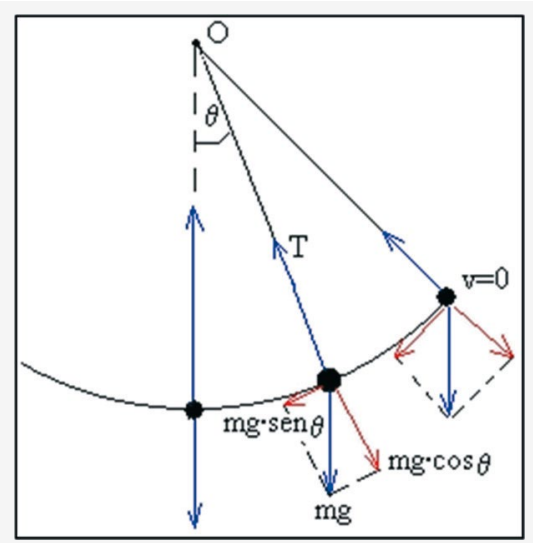

Seu movimento descreve uma trajetória em forma de arco de círculo e as forças que atuam nesse mecanismo são a força peso, que possui duas componentes uma tangencial $F n,=m g \operatorname{sen} \theta$ e outra normal $F n=m g \cos \theta$, além da força de tração no fio, que se denomina T. A componente radial é a força centrípeta e a tangencial é a força restauradora, assim como no pêndulo físico.

Fonte ilustração: Universidad del País Vasco. Disponivel em: <http://www.sc.ehu.es/sbweb/fisicaldinamicaltrabajo/pendulo/pendulo.htm >. Acesso em:11/12/2012

Este tópico apresenta a construção e simulação de um pêndulo simples composto por uma massa concentrada de $365 \mathrm{~g}$ e comprimento de $300 \mathrm{~mm}$; deslocado de sua posição de equilíbrio (eixo vertical) de um ângulo de $10^{\circ} \mathrm{com}$ a vertical e; com velocidade angular inicial igual $\omega=0$. Com o desenvolvimento desse modelo virtual, deseja-se obter a força aplicada no ponto de apoio no instante $t 0$ e a determinação da aceleração da gravidade.

\section{Etapa 1 - Inicializando o ADAMS/View}

- Inicialize o módulo, conforme discutido no item 1.3.1, e escolha a opção Create a new model.

- Em seguida, preencha a aba Model name com o nome do modelo virtual, no caso, "pendulo_simples". Veja que este é o nome do modelo virtual.

A Figura 2.18, a seguir, exibe a tela que o usuário irá obter. Ressalta-se que o nome atribuído não deve conter caracteres especiais, como acentos gráficos, símbolos, formas etc. Mantenha a aba Gravity e Units nos valores default, conforme indicado na Figura 2.18.

A aba Start in especifique o diretório no qual o database será armazenado, quando gravado. No caso, escolheu-se o diretório "Meus documentos" pasta "Minhas Formas". 


\section{Etapa 2 - Ajustando a área de trabalho no ADAMS/View}

Altere o espaçamento do grid para $25 \mathrm{~mm}$. Para tanto, recorra ao menu principal opção Settings $\rightarrow$ Working Grid aba Spacing. A tela auxiliar que aparecerá é a indicada na Figura 2.19.

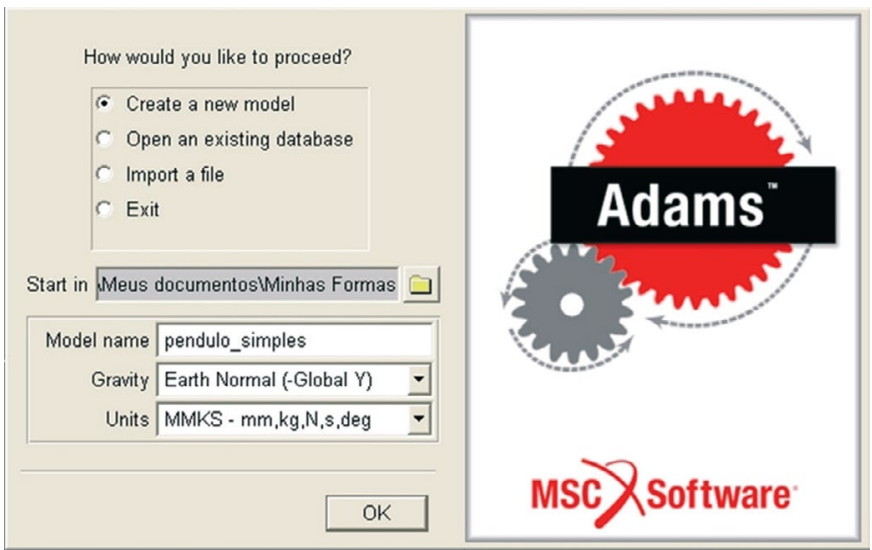

Figura 2.18 - Tela inicial do ADAMS/View.

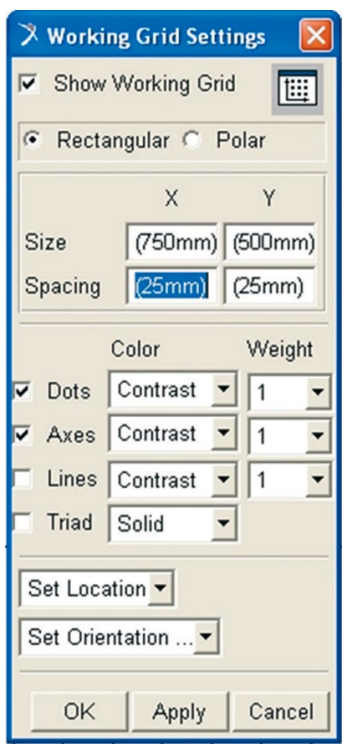

Figura 2.19 - Tela para alteração de espaçamento do grid na área de trabalho do ADAMS/View.

Etapa 3 - Construção da haste de sustentação do pêndulo simples

Para criação dessa parte, será usada a ferramenta link.

- No menu Main Toolbox, clique com o botão direito do mouse sobre o ícone $\mathscr{Q}$. 
- Dentre as opções mostradas, escolha o ícone (Rigid Body: Link). Ao escolher essa geometria, serão mostradas, na parte inferior do menu Main Toolbox, as opções de construção da peça, ou seja, Length (comprimento), Width (largura) e Depth (profundidade). Nelas, deverão ser colocadas as dimensões do link. Para acioná-las, deve-se marcá-las com um tick e preencher com os valores escolhidos, conforme a Figura 2.20.

- Atenção ao preenchimento, repare que a unidade default é o " $\mathrm{cm}$ ” e no seu preenchimento será alterada por " $\mathrm{mm}$ ".

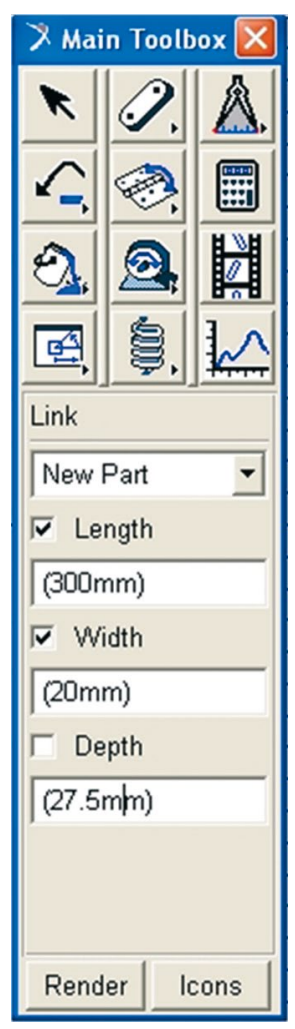

Figura 2.20 - Tela para criação do link que representará o fio do pêndulo simples.

- Clique no ponto correspondente à origem do sistema de coordenadas da área de trabalho do módulo. Essa será a coordenada inicial do link. Se houver dificuldade na seleção do ponto, posicione o cursor em qualquer região da tela e pressione a tecla F4. Isto fará com que apareça a janela Coordinates, conforme discutido na Etapa 3 do item 2.1.

- Arraste o cursor na direção vertical para baixo, para que a geometria link seja criada. A Figura 2.21 ilustra o resultado final dessa operação. 


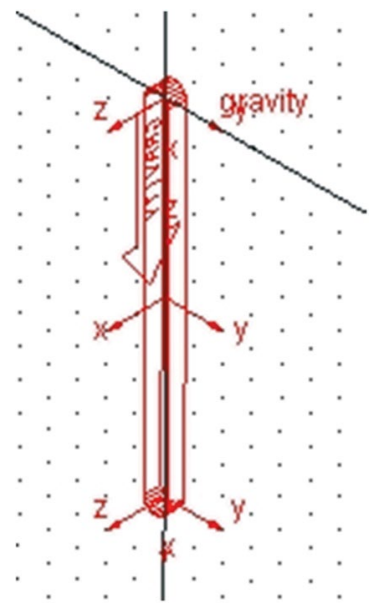

Figura 2.21 - Link criado na área de trabalho (vista isométrica).

\section{Etapa 4 - Construção da massa pontual do pêndulo simples}

A massa que será posicionada na extremidade inferior do link criado na Etapa 3 será uma esfera. Para criá-la proceda da forma descrita a seguir.

- No menu Main Toolbox clique com o botão direito do mouse sobre o ícone $\mathscr{O}$. Isto fará com que ele se expanda.

- Selecione a opção 이 . A Figura 2.22a mostra a operação.

- Preencha as informações sobre a geometria sólida conforme mostra a Figura 2.22b. Repare que, na aba Sphere, deve-se ativar a barra de rolagem ao lado e selecionar Add to Part.

- Insira a nova geometria na PART_2 no ponto de coordenada $(\mathrm{X}, \mathrm{Y}, \mathrm{Z})$ igual a $(0,-300,0)$, ou seja, na extremidade inferior do link. A Figura 2.23 ilustra esta operação. 


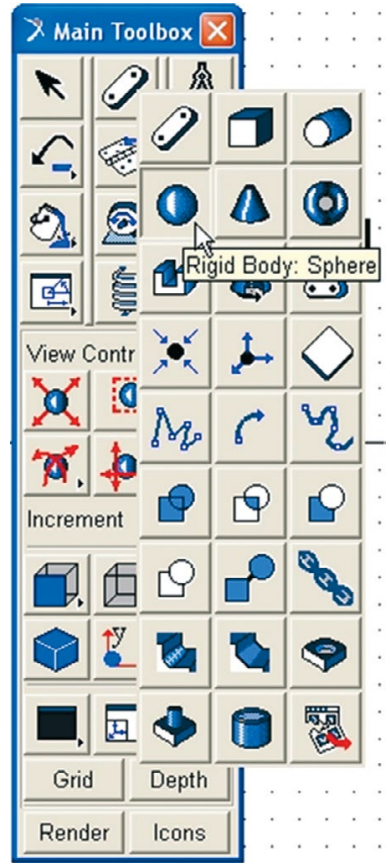

(a)

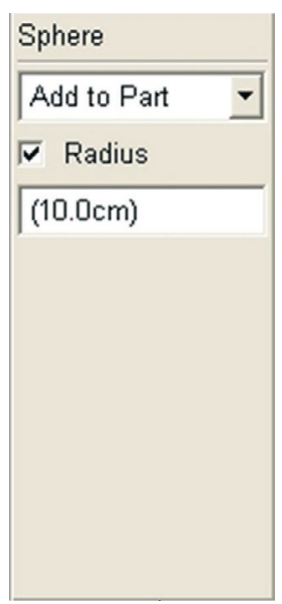

(b)

Figura 2.22 - Tela ilustrativa de criação de uma geometria sólida tipo Esfera.

\section{Etapa 5 - Alterando o nome do modelo}

- Selecione a geometria sólida PART_2.

- Em seguida, pressione o botão direito do mouse sobre ela.

- Escolha Part:Part_2, dirija-se à seta em frente à opção. Passe o mouse sobre ela para que apareçam as opções disponíveis.

- Escolha a opção Modify.

- Na caixa de diálogo Modify Body vá à aba Category, ative a barra de rolagem e selecione a opção Name and Position.

- Em seguida, vá até a aba New name e coloque simples.

- Clique em Apply e depois Ok. Esta Etapa está demonstrada na Figura 2.23 . 


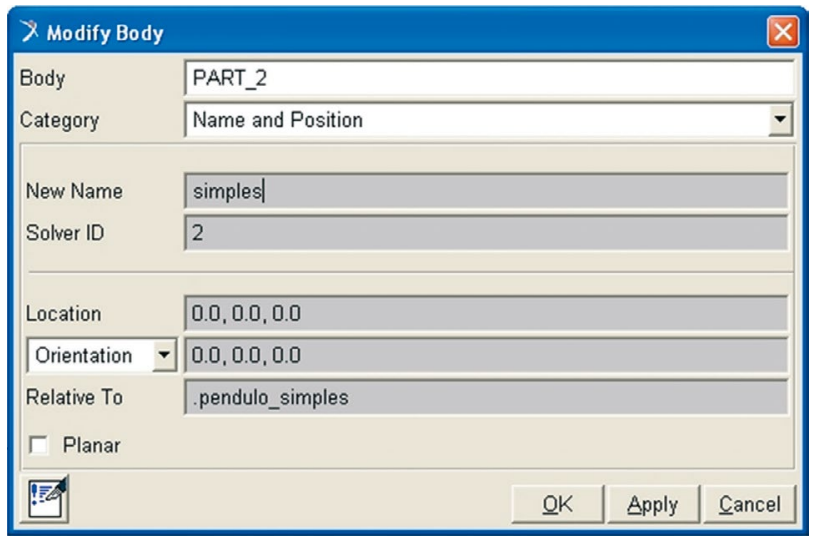

(a)

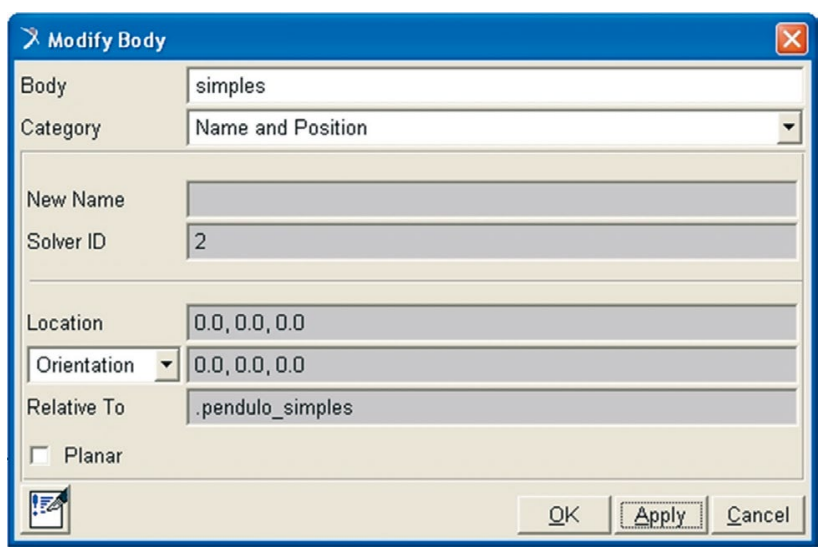

(b)
Figura $2.23-$

(a)tela de modificação do nome da parte;

(b) resultado final da operação.

Etapa 6 - Modificando a massa e a posição do centro de massa do pêndulo

Geometrias criadas no ADAMS/View vêm sempre com um valor de massa default associado a um determinado tipo de material. Nesta Etapa, será feita a alteração desse valor de massa. O novo valor, conforme definido, será de $0,365 \mathrm{~kg}$. Para tanto,

- Selecione com o botão direito do mouse a Part: simples.

- Corra com o cursor até a seta localizada em frente a essa opção. Ela irá expandir.

- Escolha a opção Modify.

- Na caixa de diálogo que se abre, vá à aba Category e se certifique de que a opção seja Mass Properties. Se não for, acione a barra de rolagem e escolha essa opção. 
- $\quad \mathrm{Na}$ aba Define Mass By, acione a barra de rolagem e selecione User Input.

- Substitua o valor que está na caixa Mass por 0.365 , e os valores de Ixx, Iyy e Izz por 0, conforme a Figura 2.24a.

- No campo Center of Mass Marker, com o botão direito do mouse, aponte até .pendulo_simples.simples.cm, conforme a Figura 2.24b e selecione Modify. Na caixa Location, preencha de acordo com a Figura 2.24c. Repare que, se clicar sobre o Apply, aparecerá uma tela de Warning o alertando da modificação do centro de massa.

- Pressione $O k$ nas duas caixas de diálogo.

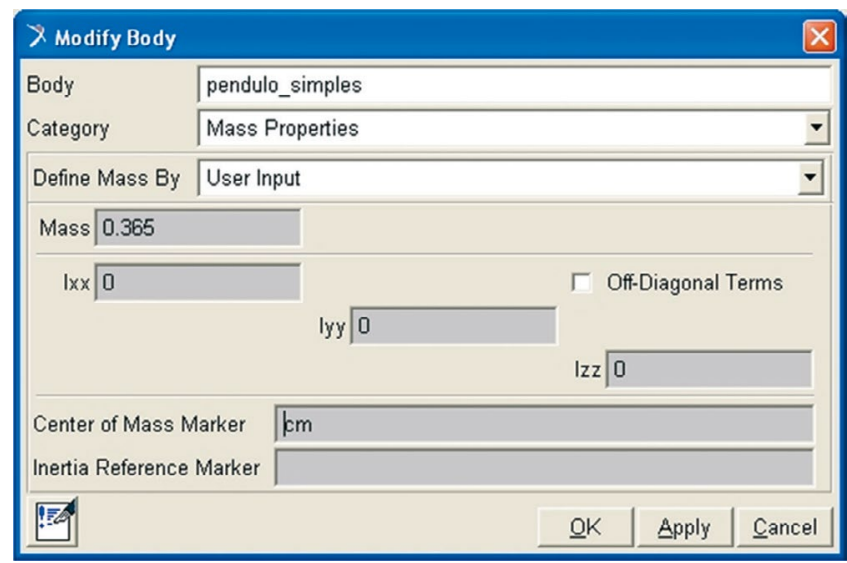

(a)

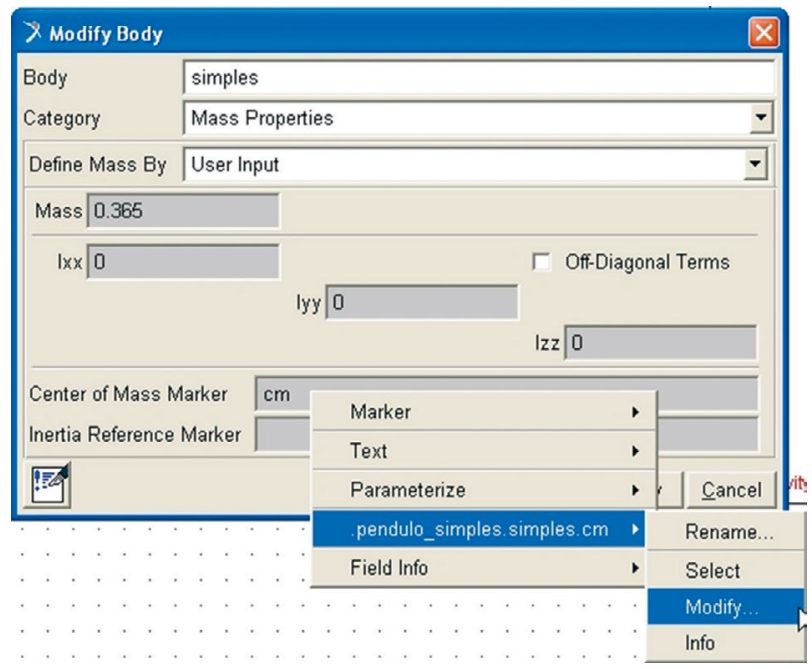

(b) 


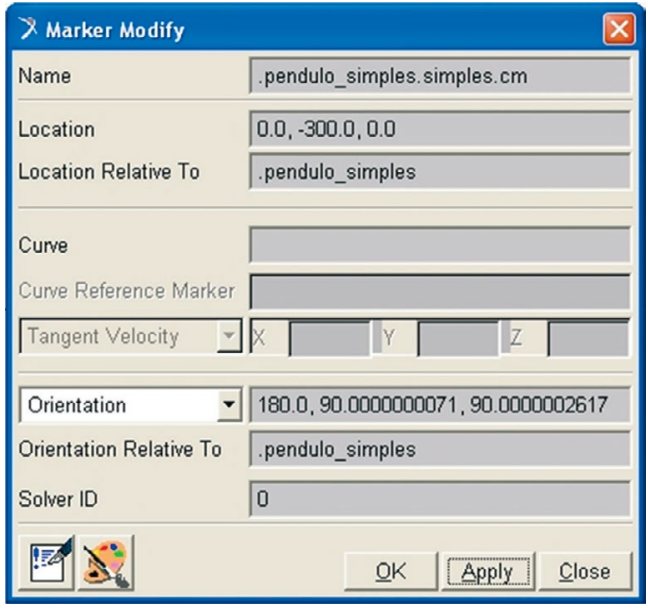

(c)
Figura $2.24-$

(a) tela representativa da modificação de massa do pêndulo simples; (b) tela representativa da modificação do marker do centro de massa do link para a extremidade inferior; (c) tela representativa da coordenada de alteração do centro de massa.

Etapa 7 - Inserindo uma junta no ponto de origem do pêndulo

Nesta Etapa, será criada uma restrição entre o link do pêndulo e o ground part. A restrição será do tipo junta revoluta tratada em 1.3.3.1a.

- Escolha o ícone referente a essa junta no menu Main Toolbox.

- Preencha as abas referentes a essa junta da seguinte maneira: Construction opção 1 Location e, em seguida, na aba logo abaixo, Normal to Grid, Figura 2.8a. Neste caso, ao fornecer a posição de inserção, o ADAMS/View automaticamente selecionará as partes necessárias para inserção da restrição, no caso o link e o ground part. O marker a ser escolhido é o simples.MARKER_1, conforme a Figura 2.25. 


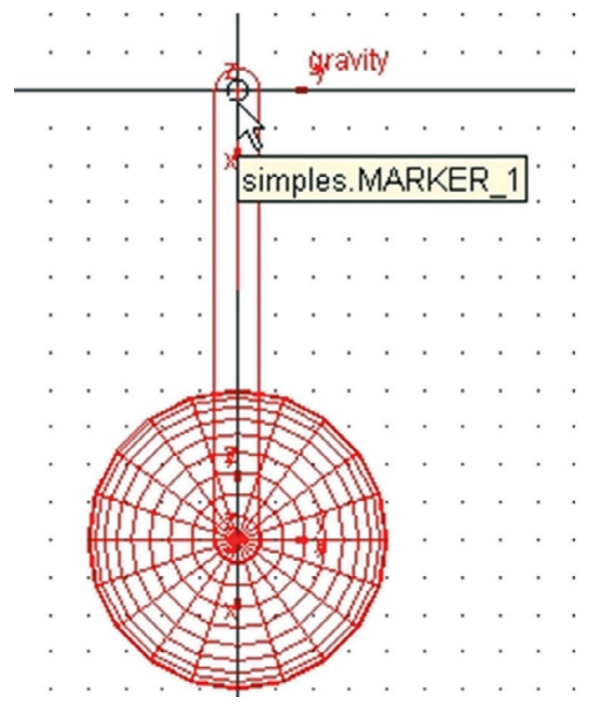

Figura 2.25 - Marcação do ponto de inserção da junta revoluta.

\section{Etapa 8 - Alterando o nome da restrição/junta}

- Clique com o botão direito do mouse na região próxima à junta inserida na Etapa 7.

- $\quad$ Selecione JOINT_1.

- Avance com o cursor até a seta ao final da opção, e ela irá se expandir.

- Em seguida, escolha a opção Rename. A caixa de diálogo ativa deve ser alterada conforme a Figura 2.26.

\begin{tabular}{|c|c|c|c|}
\hline$\chi$ Rename & & & $\underline{x}$ \\
\hline Object & pendulo_simpl & pivot & $\ldots$ \\
\hline New Name & pendulo_simp & 5. pivot & \\
\hline & $\mathrm{OK}$ & Apply & Cancel \\
\hline
\end{tabular}

Figura 2.26 - Tela ativa para renomear a junta revoluta.

\section{Etapa 9 - Estabelecendo medidas no pêndulo simples}

Nesta Etapa, serão estabelecidas os tipos de medidas que se irá determinar no modelo virtual. Para tanto,

- Clique com o botão direito do mouse na região próxima à junta inserida na Etapa 7.

- Selecione Joint: pivot.

- Avance com o cursor na direção da seta ao final da opção para expandi-la. 
- Selecione a opção Measure.

- $\quad$ Preencha a caixa de diálogo conforme a Figura 2.27.

- Clique em Apply. Esta opção irá fazer com que apareça uma tela auxiliar de nome pivot_MEA_1. Não feche a tela, pois será nela que aparecerão os resultados requeridos sobre o pêndulo.

- Para finalizar, clique em Cancel. Se clicar em Ok uma nova tela idêntica à anterior irá aparecer.

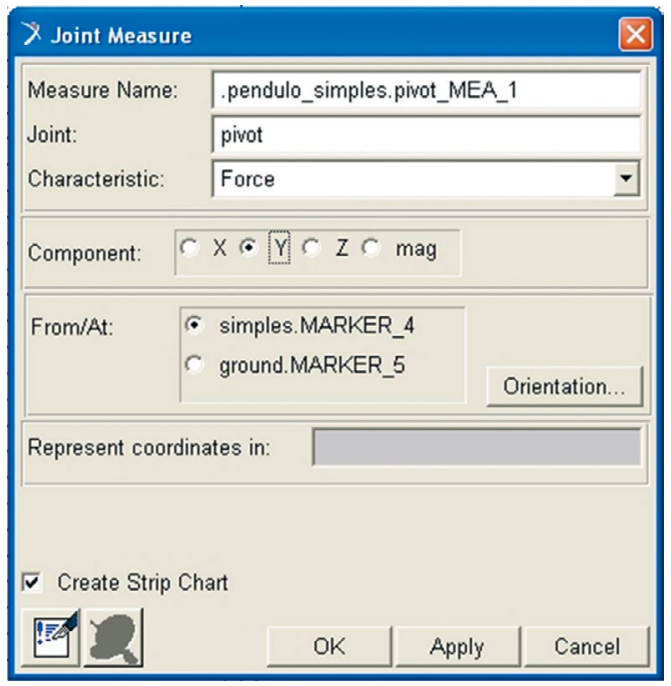

Figura 2.27 - Tela ilustrativa da escolha do tipo de medida a realizar.

\section{Etapa 10 - Criando um marker}

Nesta Etapa, serão inseridos markers em pontos chaves da geometria sólida.

- No menu Main Toolbox, acione o ícone $\mathscr{Q}$ com o botão direito do mouse.

- Escolha o ícone \$, referente à opção Construction Geomety: Marker.

- Preencha as abas que aparecerem na parte inferior do menu Main Toolbox, conforme ilustrado na Figura 2.28.

- Posicione este marker na coordenada $(0,-300,0)$. Para identificá-la, recorra à janela Coordinates, acionada com o botão F4. As Figuras 2.29a e b ilustram o resultado. 


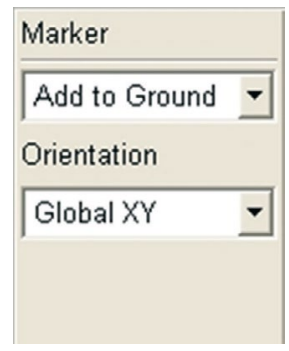

Figura 2.28 - Preenchimento de tela referente à inserção de um marker.

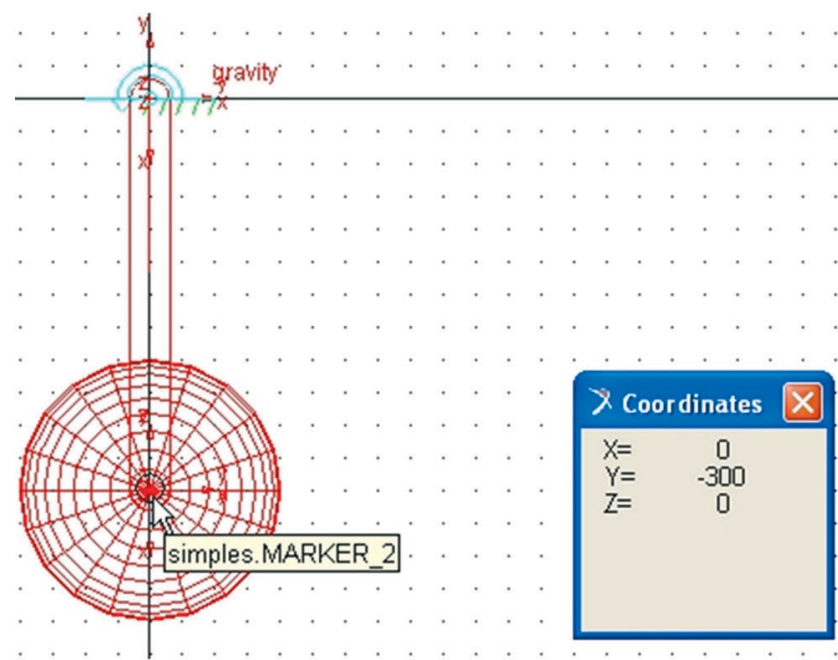

(a)

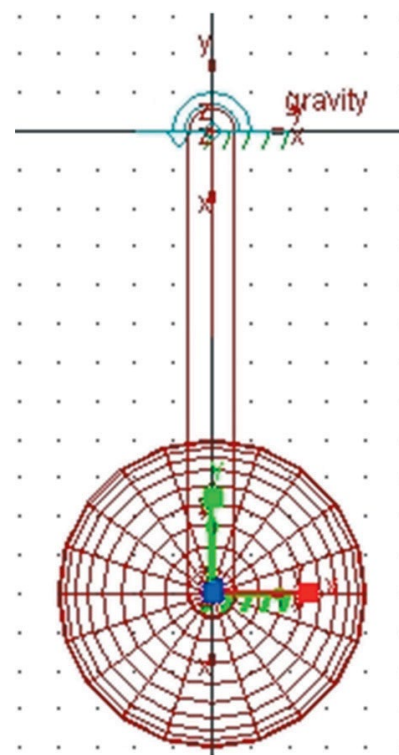

(b)

Figura 2.29 - (a) tela e inserção do marker com auxílio da função Coordinates;

(b) resultado final com marker ao centro da geometria esfera.

\section{Etapa 11 - Alterando o nome do marker}

Nesta Etapa, o marker criado na Etapa 10 terá seu nome alterado de MARKER_6 para ponto_ref. Para tanto,

- Selecione o marker criado.

- Escolha na opção Part: ground o marker denominado MARKER_6 e direcione o cursor até o final da opção para que ela se expanda.

- Escolha a opção Rename.

- Digite na aba New Name, o novo nome "ponto_ref".

- Acione a tecla Apply.

- $\quad$ Em seguida Ok. 


\section{Etapa 12 - Estabelecendo a medida de ângulos do pêndulo simples durante a trajetória}

- Vá ao menu principal opção Build $\rightarrow$ Measure $\rightarrow$ Angle $\rightarrow$ New.

$\mathrm{Na}$ caixa de diálogo acionado, demandam-se as seguintes informações: First Marker, Middle Marker e Last Marker, Figura 2.30a.

- Na primeira aba, First Marker, selecione com a ajuda do botão direito do mouse a opção Marker. Nesta aba, constará o marker correspondente à extremidade inferior do pêndulo. Seu nome é .simples. $M A$ RKER_2, Figura 2.30b.

- Na segunda aba, Middle Marker, selecione, operando da mesma forma, o marker da extremidade oposta onde se tem a junta. O nome da geometria é simples.MARKER_1,, Figura 2.30b.

- Para a última aba, selecione, operando da mesma forma, o marker criado na Etapa anterior de nome pont_ref, Figura 2.30b.

- $\quad$ Clique em $O k$.

Para o usuário, a seleção desses markers pode ser feita pressionando-se o botão direito do mouse sobre a aba ativa e escolhendo a opção Pick ou Browse.

Uma nova tabela de registro de medidas se apresenta com o nome de MEA ANGLE_1. Não feche a tela, pois será nela que aparecerão os resultados requeridos pelo usuário sobre o pêndulo.

- Para finalizar, clique em Cancel. Se clicar em $O k$, uma nova tela idêntica à anterior irá aparecer.

A Figura 2.30 ilustra as telas referentes às operações descritas aqui.

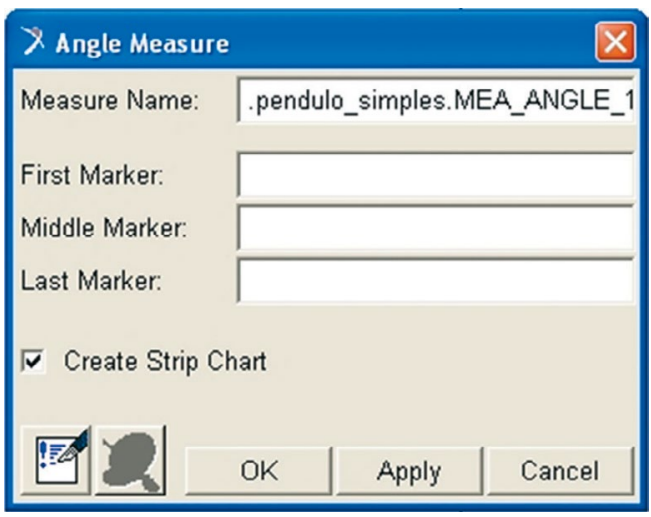

(a)

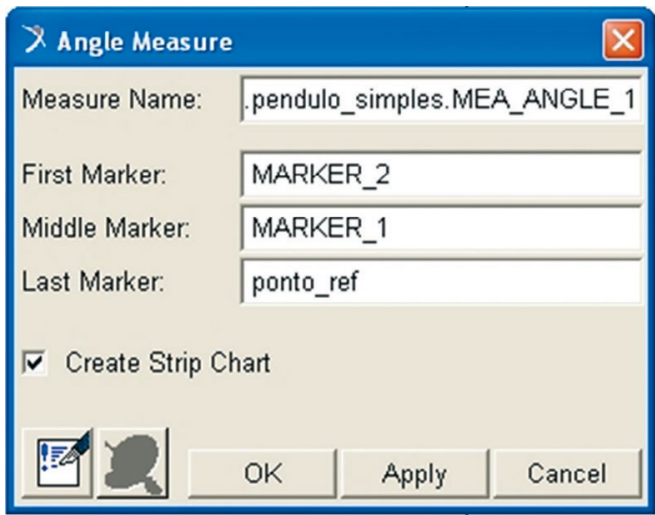

(b)

Figura 2.30 - (a) tela representativa da inserção de medidas antes do preenchimento; (b) tela final após preenchimento. 
Etapa 13 - Definindo a posição inicial para o movimento do pêndulo simples

Esta Etapa definirá a posição inicial do pêndulo simples para realização do movimento harmônico. Para tanto,

- Clique com o botão direito do mouse sobre a junta revoluta inserida na Etapa 7.

- Selecione a opção Joint:pivot.

- Arraste o cursor na direção da seta situada ao final da opção. Novas opções são apresentadas.

- Selecione a opção Modify.

- $\quad \mathrm{Na}$ caixa de diálogo Modify Joint, selecione a opção Initial Conditions..., conforme ilustra a Figura 2.31a. Todas as outras abas permanecem com os valores default.

- Clique sobre a opção e uma nova caixa de diálogo se apresentará.

- Ative a opção Rot. Displ. (Rotational Displacement) por meio de um tick no quadrado ao lado.

- Preencha a aba cinza lateral com o valor de $-10^{\circ}$, Figura 2.31 b.

\section{Etapa 14 - Verificação do modelo}

Esta Etapa se destina à análise do modelo antes que este seja submetido à simulação. Para tanto,

- Clique no ícone i. com o botão direito do mouse. Este ícone se situa no canto inferior direito da tela do ADAMS/View.

- Escolha a opção $\checkmark$. Ela verifica o modelo, fornece o número de partes e informa o número de graus de liberdade.

- $\quad$ Feche a tela correspondente se a mensagem ao final for Model verified successfully.

O usuário irá perceber que, ao final dessa Etapa, aparecerá uma tela auxiliar de nome Message Window. A mensagem é a seguinte: WARNING: Initial condition specified on JOINT pendulo_simples.pivot differs from the input configuration specified in the data set by - 10.0 degrees. A advertência se deve ao fato de terem-se alterado as condições iniciais do sistema a partir da fixação de um ângulo de inclinação inicial de $-10^{\circ}$. Clique em close. 


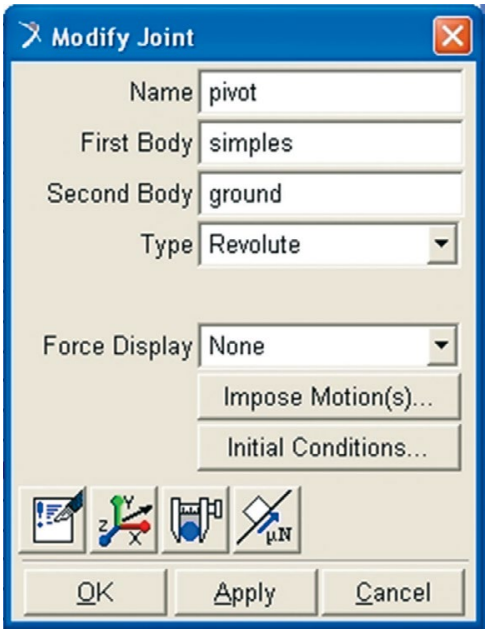

(a)

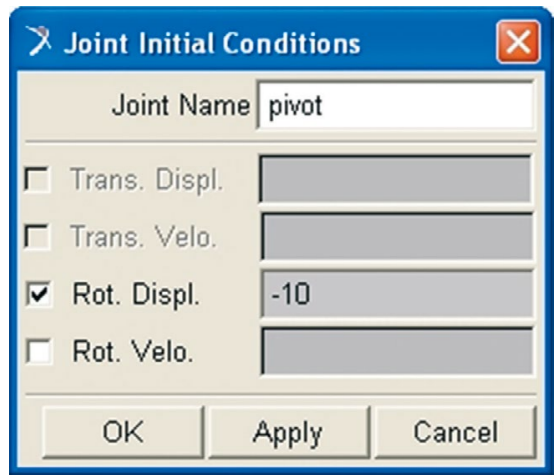

(b)

Figura 2.31 - (a) tela Modify Joint contendo a opção Initial Conditions;

(b) tela auxiliar ligada à opção Initial Conditions

\section{Etapa 15 - Efetuando a simulação do modelo virtual proposto}

- Vá ao menu principal Main Toolbox e selecione o ícone |⿴囗大미, tratado no item 1.3.4, com um simples clique sobre ele.

- Preencha as abas que aparecem na parte inferior do menu Main Toolbox, conforme mostrado na Figura 2.32a.

- $\quad$ Em seguida, clique no botão Play $\bullet$. As telas pivot_MEA_1 e MEA_ ANGLE_1 serão preenchidas, conforme a Figura 2.32b.

- Repare que, na Figura 2.32a, para tornar ativa a opção Duration é necessário ativar a barra de rolagem e a escolher, pois o valor default é End Time. 


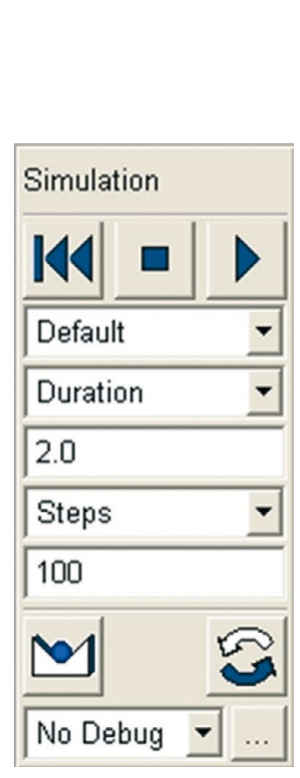

(a)

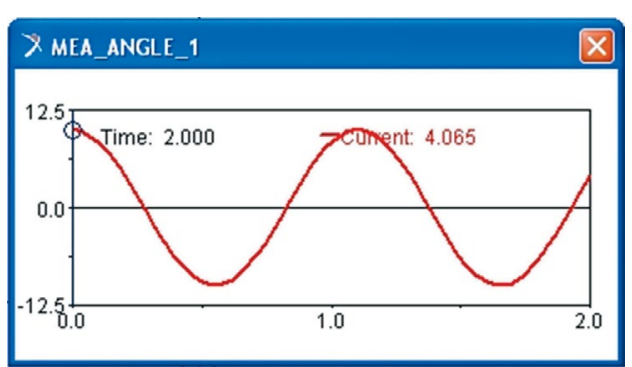

(b)

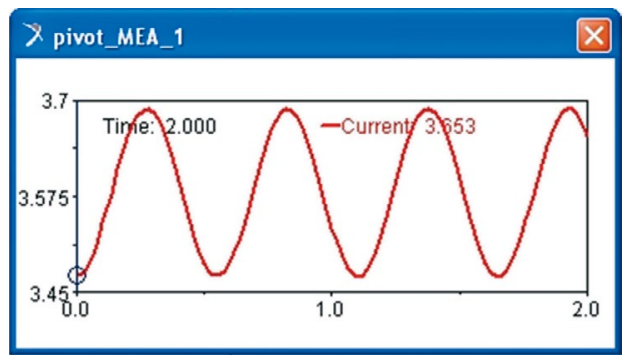

(c)

Figura 2.32 - (a) tela ilustrativa da simulação;

(b) e (c) telas auxiliares, preenchidas após execução do comando.

Etapa 16 - Determinação da força sobre o ponto de inserção da junta

Para a realização desta Etapa, será necessário recorrer ao ADAMS/ PostProcessor, tratado em 1.4.

- Clique com o botão direito do mouse em qualquer ponto da área do gráfico pivot_MEA_1.

- Aparecerá então a opção Plot:scht1.

- Expanda e selecione a opção Transfer to full plot. Nesse momento, você migrará para o módulo ADAMS/PostProcessor.

- No menu principal desse módulo, selecione a opção Plot Tracking representada pelo seguinte ícone ${ }^{*}$. Isso permitira rastrear os valores de Força $x$ Tempo ao longo da curva.

A Figura 2.12 mostra a aparência dessa janela.

Pressione a tecla F8 para retornar ao módulo ADAMS/View.

A notar: a figura mostrada a seguir traz as forças atuantes no mecanismo de pêndulo simples que são a tração no fio " $T$ " e a força peso " $P$ " que se decompõe segundo duas componentes.

$$
P_{n}=P \cos \theta \text { e } P_{t}=P \operatorname{sen} \theta
$$




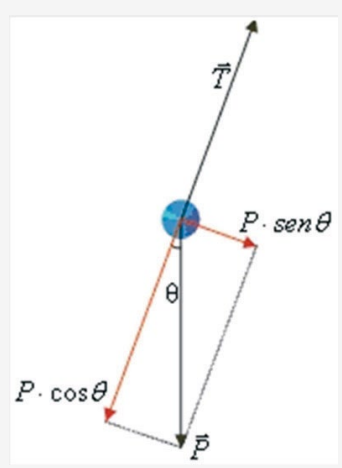

Fonte ilustração:Universidad del País Vasco. Disponível em: <http://www.sc.ehu.es/sbweb/fisical dinamicaltrabajo/pendulo/pendulo.htm >. Acesso em:11/12/2012

O equilibrio na direção normal leva a $\mathrm{Pn}=T$ que fornece o valor da tração no fio $e$, consequentemente, a força no ponto de apoio (junta revoluta). Então, analiticamente, na posição $x=0$, coincidente com o eixo vertical, a força é igual a 3,51N, considerando $m=0,365 \mathrm{~kg}, g=9,81 \mathrm{~m} / \mathrm{s} 2$ e cos $\left(-10^{\circ}\right)=0,98$. Pela simulação numérica, este valor no mesmo ponto foi igual a 3,47 N, ou seja, bem próximo.

A curva que descreve o movimento harmônico do pêndulo na direção y gerado pelo ADAMS/PostProcessor é a mostrada a seguir. Cabe ressaltar que o movimento harmônico só se confirma no pêndulo se os ângulos considerados forem pequenos.

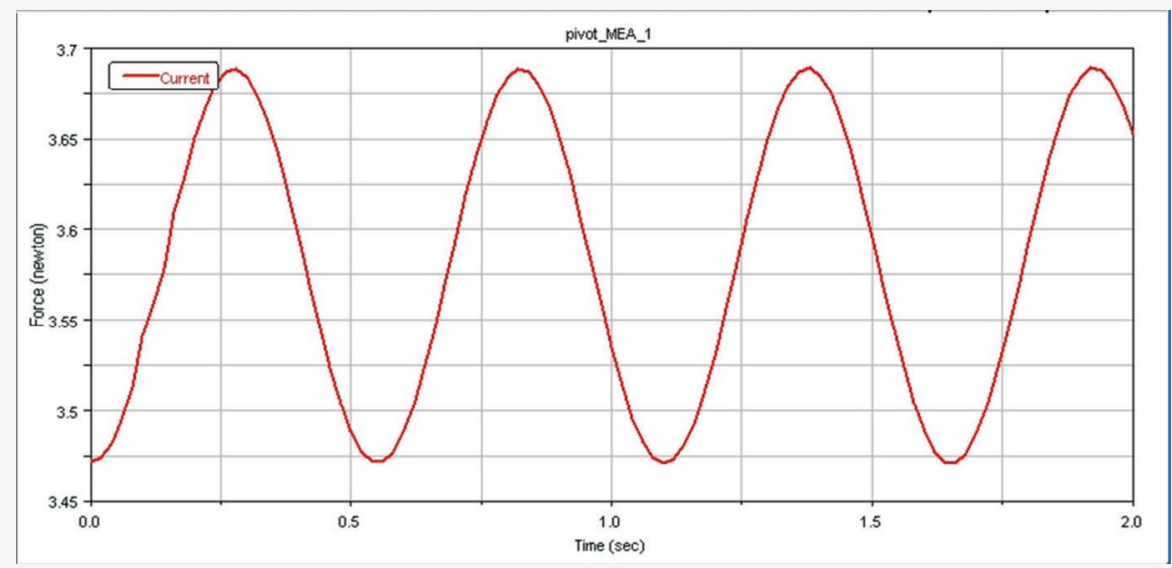

Ainda da avaliação de forças, nota-se que a única força responsável pelo movimento oscilatório é $F_{t}=P \operatorname{sen} \theta$.

O periodo de oscilação Té o tempo necessário para a massa passar duas vezes consecutivas pelo mesmo ponto, movendo-se na mesma direção, isto é, o tempo que a massa leva para sair de um ponto e voltar ao mesmo ponto percorrendo o mesmo arco. O pêndulo descreve uma trajetória circular um arco de circunferência de raio L. Um pêndulo simples é formalmente equivalente a um oscilador linear. Pode afirmar então que: 


$$
T=2 \pi(L / g)^{0,5}
$$

onde $L$ é o comprimento da haste de $0,30 \mathrm{~m}$, no caso $T=1,10 \mathrm{~s}$, enquanto a frequência é de 0,91 Hz. Portanto a aceleração da gravidade é dada por $g=\left(4 \pi^{2} L\right) / T^{2}$.

\section{Etapa 17 - Determinação da aceleração da gravidade}

Nesta Etapa a aceleração da gravidade será determinada a partir do período de oscilação do pêndulo simples. Os dados referentes ao período são calculados pelo ADAMS/View no marker criado na Etapa 10. Para tanto,

- Feche a janela de medidas pivot_MEA_1.

- No menu principal Main Toolbox, selecione o ícone 圈, tratado no item 1.3.4, com um simples clique sobre ele.

- Preencha as abas que aparecem na parte inferior do menu Main Toolbox, conforme mostrado na Figura 2.33.

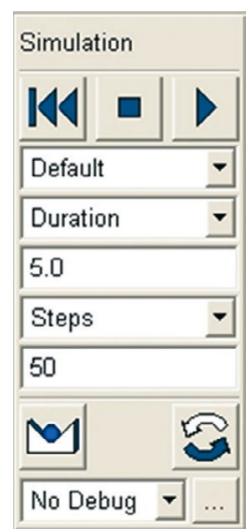

Figura 2.33 - Tela ilustrativa dos campos de preenchimento para simulação para obtenção do período.

Em seguida, clique no botão Play . Nesse instante, a simulação será efetuada e aparecerá a seguinte tela, conforme a Figura 2.34.

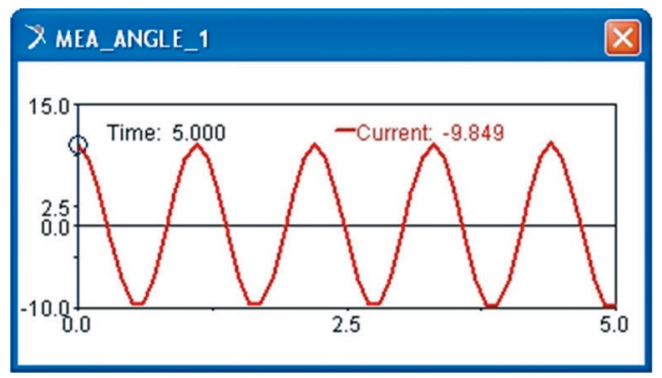

Figura 2.34 - Tela ilustrativa da simulação de obtenção do período. 
O usuário irá perceber que, ao final dessa Etapa, aparecerá uma tela auxiliar de nome Message Window. A mensagem é a seguinte: WARNING: Initial condition specified on JOINT pendulo_simples.pivot differs from the input configuration specified in the data set by -10.0 degrees. A advertência se deve ao fato de ter-se alterado as condições iniciais do sistema a partir da fixação de um ângulo de inclinação inicial de $-10^{\circ}$. Clique em close.

- Clique com o botão direito do mouse em qualquer ponto da área do gráfico MEA_ANGLE_1.

- Aparecerá então a opção Plot:scht1.

- Expanda e selecione a opção Transfer to full plot. Nesse momento, você migrará para o módulo ADAMS/PostProcessor. A Figura 2.35 ilustra o gráfico do período obtido.

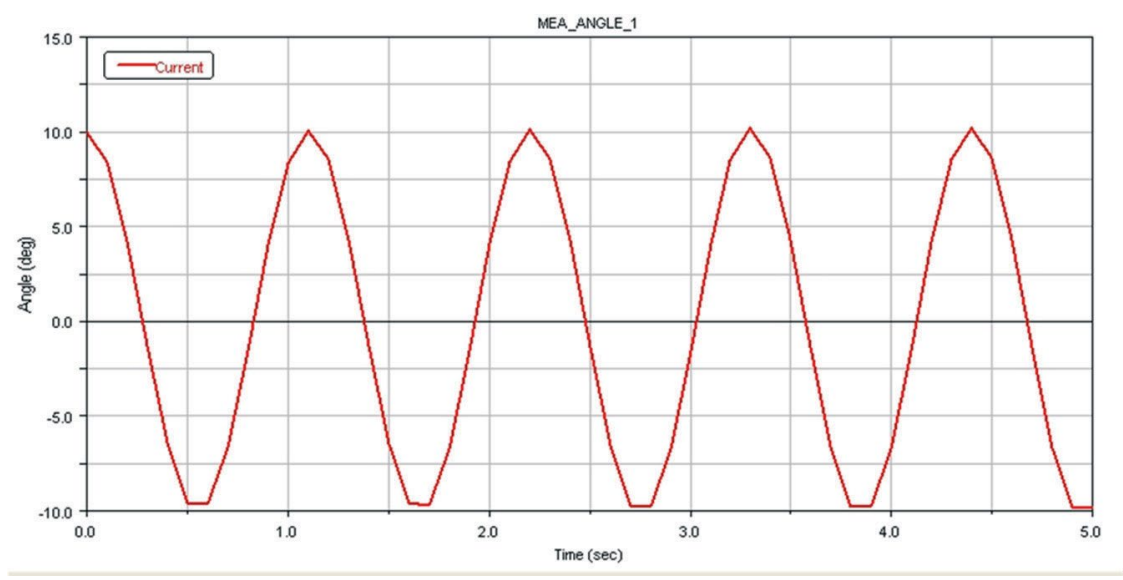

Figura 2.35 - Tela ilustrativa da simulação de obtenção do período no módulo ADAMS/PosProcessor.

- No menu principal desse módulo, selecione a opção Plot Tracking, representada pelo seguinte ícone \# . Isto possibilitará, ao usuário, rastrear os valores de Ângulo $x$ Tempo, ao longo da curva. A Figura 2.36 mostra o tempo que o pêndulo leva para percorrer a distância correspondente a dois picos da curva, o que fornece o período. 


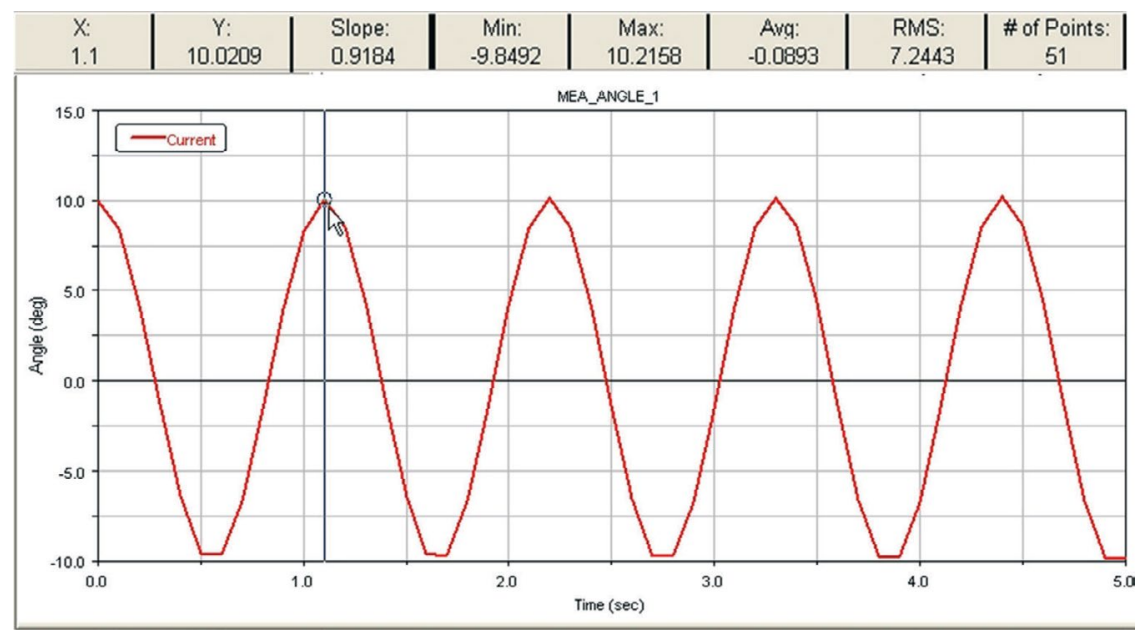

Figura 2.36 - Tela ilustrativa da simulação de obtenção do período no módulo ADAMS/PosProcessor, destacando o ponto de obtenção do período $X=1.1 \mathrm{~s}$

Sabendo que $g=\frac{\left(4 \pi^{2} L\right)}{T^{2}}, T=1,1 s$ obtido da Figura $2.36, L=0,30 \mathrm{~m}$, disto tem-se $g=9,79 \mathrm{~m} / \mathrm{s}^{2}$.

\section{Etapa 18 - Salvando o modelo virtual}

Após finalizar a simulação, o usuário deverá salvar seu trabalho, procedendo da seguinte maneira:

- Vá ao menu principal do módulo e selecione a opção File.

- Clique sobre ela e a faça expandir.

- Escolha a opção Save Database as...

- Clique sobre ela, e uma tela irá se abrir, conforme a Figura 2.13. 
